\title{
Metabolomics: An Emerging Tool for Precision Medicine
}

\author{
Anna Meiliana ${ }^{1,2,}$, Nurrani Mustika Dewi², Andi Wijaya ${ }^{1,2}$ \\ ${ }^{1}$ Postgraduate Program in Clinical Pharmacy, Padjadjaran University, Jl. Eijkman No.38, Bandung, Indonesia \\ ${ }^{2}$ Prodia Clinical Laboratory, Jl. Cisangkuy No.2, Bandung, Indonesia \\ *Corresponding author. E-mail: anna.meiliana@prodia.co.id
}

Received date: Jun 10, 2020; Revised date: Dec 2, 2020; Accepted date: Dec 3, 2020

\section{Abstract}

$\mathrm{B}$ ACKGROUND: Metabolomics is a developed technology that comprehensively analyzes the metabolites in biological specimens. It appears to be a prospective method in the practice of precision medicine.

CONTENT: Metabolomic technologies currently surpass beyond the traditional clinical chemistry techniques. Metabolomic is capable to perform a precise analysis for hundreds to thousands of metabolites, therefore provide a detailed characterization of metabolic phenotypes and metabolic derangements that underlie disease, to represent an individual's overall health status, furthermore to discover new precise therapeutic targets, and discovery of biomarkers, either for diagnosis or therapy monitoring purpose.

SUMMARY: Adequate data processing and quantification methods are still needed to be developed to boost integrated -omics as a powerful clinical practice platform.

KEYWORDS: metabolomic, precision medicine, phenotyping, biomarker, nutritional pattern

Indones Biomed J. 2021; 13(1): 1-18

\section{Introduction}

Precision medicine aims to design disease prevention and clinical care strategies based on individual environments, lifestyles, genetics, and molecular phenotype variability. Since 1957, the Central Dogma of molecular biology set an impact in life sciences. However, at that moment, Central Dogma didn't catch the idea of small molecule composition in the cells, which play the actual role in controlling the function of genes, transcripts, and proteins, as well as the macromolecules activities regulation in a complex feedback circuit. The interaction between small molecules and the cells' macromolecular components is the main determinant of cell function or dysfunction.(1)

Metabolomics is a comprehensive measurement of all metabolites in biology specimens, including parent compounds and their low-molecular weight molecules $<1000 \mathrm{Da}$, such as amino acids, monosaccharides, small lipids, cofactors, vitamins, energy cycle intermediates, nucleotides, and exogenous xenobiotics. The numbers of metabolites profiled by metabolomics are much larger than standard clinical laboratory techniques, so we can describe more comprehensive coverage of biological processes and metabolic pathways to consider the strategies for precision medicine.(2)

Currently, clinicians only have a small piece of information about human metabolism based on the routine blood chemistry analytes measurement.(1) Updated information from complex interactions between genotype, lifestyle, diet, nutrition, drug therapy, environmental exposure, and gut microflora at the molecular level, provide new insight into disease pathophysiology and drug response mechanism in clinical practice to predict both risk of toxicity and beneficial responses to drug treatment.(3-15) However, even after 20 years, there are still so many barriers to face in translating -omics technologies in clinical practice.(16)

In this narrative review, we discuss the current knowledge about metabolomic as the latest tool in -omics family, together with its challenges and future, especially 
in its application for biomarker discoveries, nutritional management, and precision medicine related to metabolic diseases.

\section{Metabolomics is An Emerging Technology}

"Omics" approaches, including genomics, transcriptomics, proteomics and metabolomics, recently have become important tools to integrate genetic, protein, metabolite, cellular and pathway events in flux and interdependent in one system to develop a better understanding of the complex biological processes.(17-22) The "omics" approaches measure multiple genes, transcripts, proteins, or metabolites changes simultaneously and provide an overview of various physiological or pathological conditions.(23) These advanced techniques could bring a big change in clinical setting for human diseases' diagnosis and treatments with full consideration of the limitations.(24) Metabolomics and metabonomics are two terms that are often used interchangeably.(25-28) In brief definition, metabolomics measure all metabolites in the cell, while metabonomics asses the change due to metabolic responses, or in other word, metabolomic profiling. $(1,17,29-32)$ Metabolome profiling is typically performed either by targeted or untargeted methods. Targeted and semi-targeted metabolomics focus on selected metabolites based on a hypothesis-driven approach, while untargeted metabolomics pursues an unbiased screening of all metabolites and hypothesis-free. Therefore, a combination of both approaches is preferred for a thorough metabolome capture. $(16,33)$

As the changes in the genome, transcriptome and proteome do not always result in altered biochemical phenotypes, metabolomics may in fact provide the most "functional" information of the omics technologies, with the facts that the metabolome represents the final "omic" level in a biological system, and metabolites represent functional entities which have a clear function in the life of the biological system and are also contextual, reflecting the surrounding environment.(28) Metabolomics has the capacity to increase the readouts by orders of magnitude compared with traditional chemical or even genetic screening.

As the emerging omics tools, metabolomics is less evolved compared to the other family, and in practice send quite a challenge. It targets a big range of divergent molecule physical properties, with different polarity from very water-soluble organic acids to very nonpolar lipids.
(34) A comprehensive metabolomic technology platforms prepare the sample pre-analytic and analytical procedures specifically and divide metabolomes into subgroups of metabolites, either by the polarity, common functional groups, or structural similarity as illustrated in Figure 1, and the methods used in metabolomics still continue to evolve and improve each year.(35) Current techniques used in metabolomics such as liquid chromatography-mass spectrometry (LC-MS) can measure tens to hundreds of metabolites with excellent precision, make it possible for rapid discovery and validation of early metabolic indicators of human disease, even years before the symptoms are clinically seen, for example, pancreatic cancer (36), type 2 diabetes (17-20,37), memory impairment (20). Metabolomics studies also reveal our understanding of diet and disease relationships, such as the link between elevated branched-chain amino acids (BCAA) and obesity to insulin resistance.(34) A previous study brought microbiome into the metabolite profiling and found that elevated plasma levels of trimethylamine-N-oxide, which is abundant in red meat, was associated with the composition of the gut microbiome and risk for cardiac events. $(2,35)$

While metabolomics technology is still developing, recent studies are also observing what actually constitutes the human metabolome. The complete set of small molecules in human body may exceed 19,000 (38), consist of metabolites derived from endogenous enzymatic activities encoded by the human genome, and also exogenous metabolites from food, medications, the microbiota that inhabit the body, and the environment. Nine of the 20 amino acids our body needs was depend on diet, because even we have the codons in our body but not the endogenous biosynthetic route, and this fact highlight how the exogenous metabolites are important to be counted.(2) Liquid chromatography and gas chromatography coupled to mass spectrometry (GCMS and LC-MS) and nuclear magnetic resonance (NMR) spectroscopy improve the capabilities for holistic metabolic profiling for precision medicine. The platform should be stable and reproducible, and recent studies showed the capability now possible for robust and high-quality data generation. $(33,36)$

Like any other its predecessors, there are still some bottlenecks in metabolomics to be translated clinically, especially in precision medicine, such as the general quality assurance and quality control standards, systematic errors assessment, universal workflow, big data integration and collection platform, reproducible data analysis and interpretation, and potential bioethical issues. Despite the current challenges, quantified metabolomics data 


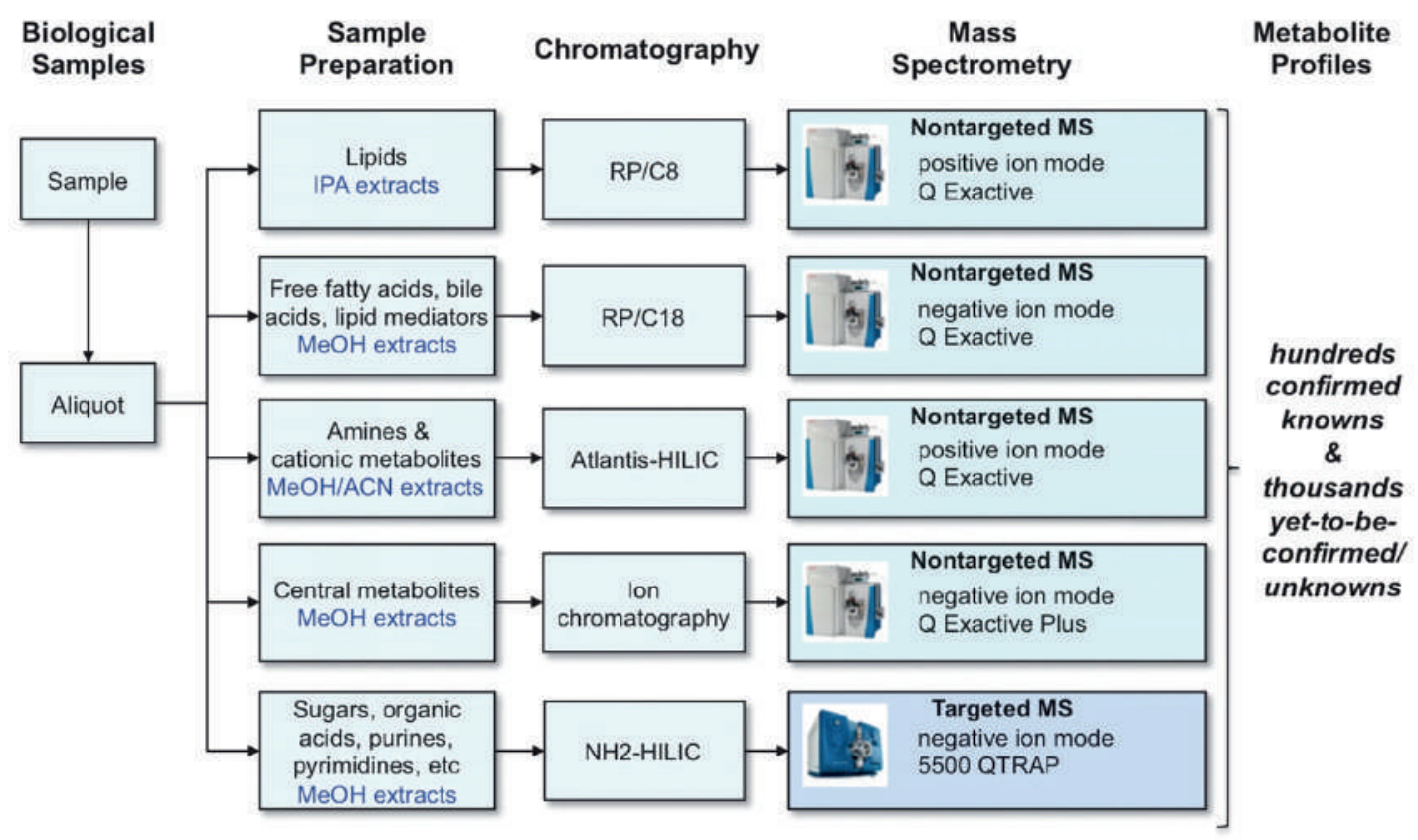

Figure 1. Illustration of the liquid chromatography-mass spectrometry (LC-MS)-based metabolomics platform.(2) (Adapted with permission from Cold Spring Harbor Laboratory Press).

have significant translational opportunities in biomarker discovery, precision nutrition and precision medicine, due to its advantages to detect responses even when growth phenotypes are lacking.

\section{Metabolomics Analysis for Biomarker Discovery}

Metabolome was first coined in 1998 as the set of metabolites (low molecular weight compounds) synthesized by cells, tissues, organs or organisms, dependent and varying according to the physiology.(29) Metabolome can be divided into several fractions: the endogenous metabolome, which is naturally produced by an organism, and the exogenous metabolome, which are chemicals that are not naturally produced by an organism, includes all foreign metabolites derived from drugs, pollutants and dietary compounds. $(1,39,40)$ The endogenous metabolome is subdivided as primary metabolome includes all metabolites characteristic of each cell type, tissue, organism, or biological fluid, reflecting particular environmental conditions and evolving according to physiological demands, and secondary metabolome which is the microbial metabolome produced by the microflora.

Thus, the metabolic phenotype consists of the integration of individual's genetic, nutritional, pharmacological, and environmental status. $(1,41,42)$
Indeed, the biochemical pathways of metabolites, as well as knowledge of their intracellular fluxes ought to be understood because the production and degradation of metabolites are regulated in interconnected distinct metabolic pathways.(41-43)

The fact that metabolites is closely related to phenotype, and that metabolome is sensitive to many factors, make it feasible for a large range of applications including diagnosis and identification of certain metabolites which characterize distinct pathological and physiological states (11,32,44-46), added with the assumption that metabolites are important players in biological systems and the disruption of biochemical pathways induce diseases. Metabolomics results in multiple metabolites assessment, thus metabolomics offers potential advantages in sensitivity and specificity in the clinical area compared to classical diagnostic approaches and conventional clinical biomarkers.(47)

An ideal biomarker is expected to fulfill some criteria included: present in minimally invasive and readily available sources such as blood or urine; highly sensitive and specific, means allow early diagnosis and unaffected by external or comorbid conditions; precisely change in response to treatment and disease progression; it provide a better understanding about the disease mechanism; and helpful in disease risk stratification and prognosis.(27) The central dogma of molecular biology explains that DNA (genes) are transcribed to mRNA (transcripts) and translated into 
proteins, then the protein activity results in small molecules (metabolites) formation.(29) Therefore, any changes in genes or proteins will affect a change in the metabolism and these were the "omics" complementary sciences all about (48), and metabolomics is applied for the nutritional and physiological status of the patient by measuring the variety of small molecules. The current metabolomics analysis tools allow a large number of samples measurement in a high-throughput manner, so it provides us the understanding of current molecular response of a biological system to any perturbation in its microenvironment $(49,50)$, explain the basic mechanisms of diseases at once able to identify the molecular markers for the diseases (1). Metabolite biomarkers can be classified into three different classes: predictive biomarkers to determine who in the population might respond to specific treatment regimes, prognostic biomarkers to observe the prospect of the disease in a patient, and pharmacodynamics biomarkers to evaluate the outcome of the treatment.(16)

\section{Metabolomics as A Tool in Nutritional Research}

The comprehensive approach of metabolomics made possible of exploring the complex interaction between human and diet, complete with the implications and subtle changes in metabolism activated by foods, nutrients and disease. In general, metabolomics application in nutrition application is divided into three categories: studies for dietary biomarker discovery, studies of diet-related diseases, and studies for dietary intervention.(51)

Overall, most metabolomics studies recently observe the disturbances in metabolic pathways (52), to find out how nutrition influences metabolism and homeostatic control and to find the early phase disturbance on this regulation, related to early detection of diseases (53). Commonly the studies performed by three approaches: acute intervention, cohort, and dietary patterns and metabolic profiles association

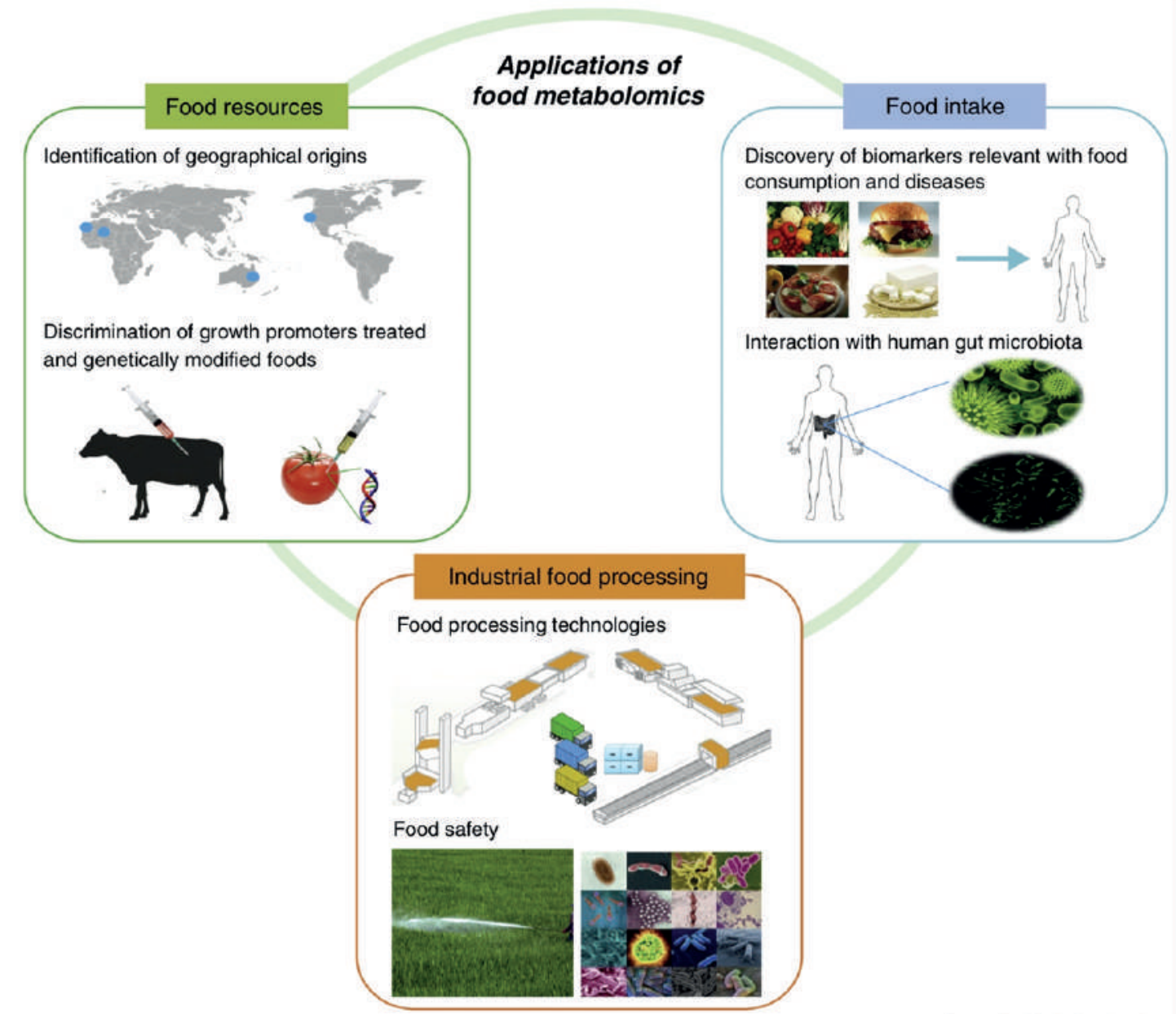

Figure 2. The three main applications of food metabolomics, from farm to human: food resource production, industrial food processing and food intake by humans.(60) (Adapted with permission from Wolter Kluwer Health). 
analysis. Attempts on self-reporting dietary assessment currently such as food-frequency questionnaires (FFQs), 24-h recalls, weighed food records cannot be fully reliable due to energy under-reporting, recall errors and difficulty in assessment of portion sizes.(54,55) Thus, biomarkers for dietary intake are needed to improve the dietary assessment. Currently, we have biomarkers for salt, protein, sucrose and fructose intake (sodium/nitrogen/sucrose and fructose measured in $24 \mathrm{~h}$ urine samples), and for energy expenditure (the doubly labeled water technique) $(56,57)$, which were extremely useful to validate the previous self-reports (57). Food metabolomics is the application of metabolomics application in human food systems, including food resources, food processing and diet. Food systems are evidently related to nutrition and human health directly. Hence, metabolomic not only useful for biomarker discoveries but also to elucidate the underlying mechanisms of disease development.(58) For instance, a number of possible risk factors of type 2 diabetes mellitus have been identified by metabolomics involving lipid molecules such as free fatty acids, bile acids and amino acids, and notably BCAA, which is correlated with insulin resistance in human and rodents. $(34,59)$ A study found an elevated levels of BCAA in obese subjects, suggest due to increased catabolism of BCAAs or
'BCAA overload'.(34) The three main applications of food metabolomics, from farm to human include food resource production, industrial food processing and food intake by humans (Figure 2).(60)

Food processing in food system used in food industries to increase food safety; to change or modify food textures, tastes, flavors, colors, etc.; and to provide nutritional or balanced diets for customers by using all techniques and methods to convert food resources such as crops, vegetables, fruits, meat and milk into valuable food products.(61) Figure 3 shows one example of the workflow of food metabolomics.

Many studies on new metabolite biomarkers correlated with dietary intake patterns such as juice (62), fruits, vegetables (63), grain, fish (64), wine (65) coffee (66) and the complex ones $(67,68)$ revealed that either specific food intake or the complex dietary pattern significantly affect human metabolism like amino acid and lipid metabolism, related to human health. Therefore, metabolomics is useful for nutritional epidemiological studies to effectively analyze the effect of specific food consumption and dietary patterns on metabolic changes. The application of metabolomics will be wider in food sciences and technology, delivering food from the farm to human, including food resource

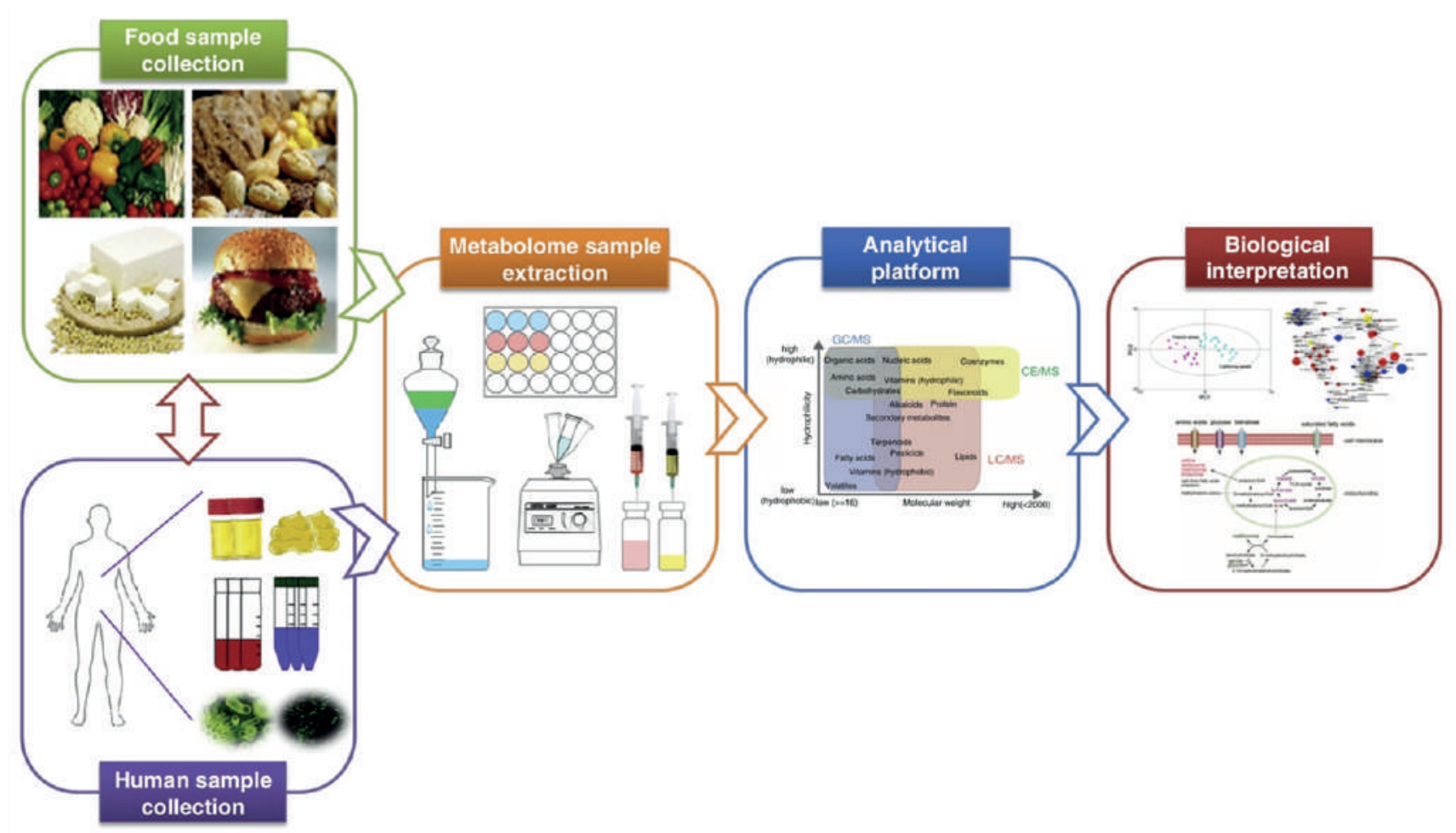

Figure 3. The workflow of food metabolomics consisting of food and human sample collection, metabolome sample extraction, instrumental analysis using analytical tools and statistical analysis of metabolic data and their biological interpretation.(60) (Adapted with permission from Wolter Kluwer Health). 
production, industrial food processing and food intake. Comprehensively, metabolomics will result in personalized food practice from design up to final products.

\section{Metabolomics Profiles and Nutritional Patterns}

Nutrition is essential in human metabolism and health, thus considered as one major factor contributes in metabolic diseases. Metabolomics is used for nutritional studies to profile all low-molecular-weight metabolites in biological samples to better understand how a stimulus could affect metabolic pathways. $(69,70)$ Many studies observed the impact of single nutrients or single foods, up to global diets or dietary patterns such as the Mediterranean diet on chronic diseases to find the link between diet and the diseases.(67)

Principal component analysis (PCA) is utilized to depict a portrait of a population's dietary patterns (71) such as the Prudent (or Healthy pattern), the Western dietary pattern, and so on, which are positively or inversely correlated with cardiovascular disease risk factors and mortality (72-74). A dietary pattern such as foods that high in sugar-sweetened soft drinks, or refined grain, processed meats and low vegetable intake was associated with the risk of type 2 diabetes mellitus.(75) Though we have not had a full understanding of the pathways underlying metabolic risk factors in humans, yet we know those are likely related to derangements in primary metabolism. More recent technologies apply LC-MS to acquire highthroughput metabolic status profiles of organisms and a comprehensive assessment of molecules of substrates or products of metabolic pathways (i.e., metabolomics).(7680) By having a complete profile of individual metabolites, we can elucidate specific metabolites' role in metabolic disorders development and its sequelae.(81-84)

There are many dietary guidelines to promote wellbeing and prevent chronic diseases. Most researches focus only on individual food or nutrient, while in fact quality of a diet is influenced by the combination of foods, its quantity, and also interrelations. $(68,85,86)$ Diets in their complexities can be summarized in patterns.(87-91) Therefore, studies should focus more on these patterns in relation to the health benefits.(92) Due to its potential to measure a range of small molecules present in a biological system, nutritional metabolomics combined with multivariate statistical analysis, can characterize and define the normal physiologic variation profiles and the changes in different biofluids as a result of specific dietary interventions.(93-95) A recent application on nutritional metabolomics has shown its potential in the identification of dietary biomarkers (96), as long as it's qualified to be replicated in future studies and comply to a classical measurement model. Moreover, metabolomics has the advantages of highlighting which metabolites and pathways are influenced by diet, thus dietary pattern-disease relations could be further explored. $(97,98)$ Biocrates Life Science AG (Innsbruk, Austria) developed AbsoluteIDZ kit, which allows more than 160 targeted metabolites in over 4 compound classes quantification in an easy, reliable and robust way. The 4 months reproducibility is good, and data showed a single measurement is sufficient for risk assessment in epidemiologic studies using healthy subjects.(99) Hence, we could collect data on metabolite properties to create a dietary biomarker classification (i.e., recovery, concentration, replacement, or predictive biomarkers).(59,93,100)

\section{Metabolomics Profiles and Obesity}

Obesity is a worldwide problem. The technology development spoiled most people's lifestyle and contributed to obesity increasing number, in line with its metabolic comorbidities, especially the risk of insulin resistance, hypertension and dyslipidemia, and mortality rate.(100) However, $10-30 \%$ of obese population have a relatively healthy metabolic status, with normal insulin sensitivity, blood pressure and lipid profiles.(101,102) These metabolically healthy obesity (MHO) group compared to the metabolically abnormal obesity (MAO), also shown a lower mortality rate and lower risk of developing metabolic disease.(103-105) Many studies aim to determine the underlying mechanisms that differentiate normal subjects, MHO and MAO subjects. Metabolomics could be used to quantitatively analyze the substantial differences in circulating markers of amino acid (106-109) and lipid $(107,109)$ metabolism, to understand how metabolites reflect physiological states. Perturbation in these metabolic pathways also reflects not only established cardiometabolic risk biomarkers, independently of weight status $(110,111)$, but were also predictive of future disease (112-114).

Many factors can modulate metabolites in its pathways, either genetic factors, environmental factors or gene-environment interactions.(115) Mass spectrometrybased metabolite profiling was applied to investigation of serum metabolite concentrations between normal $(\mathrm{Nw})$, overweight (Ov), and obese (Ob) group with metabolic disturbance (MetS) and not, and showed that there were three 
principal factors explaining a maximum of variance between groups. First, the score of long-chain glycerophospholipids metabolite is higher in $\mathrm{Ov} / \mathrm{Ob}$ with MetS compare to $\mathrm{Ov} / \mathrm{Ob}$ and Nw subjects without MetS. This factor also positively correlated with plasma total cholesterol (total-C) and triglyceride levels in the three groups, and high-density lipoprotein-cholesterol (HDL-C) only in subjects without MetS. The second factor is amino acids and short to longchain acylcarnitine which was positively correlated with HDL-C and negatively correlated with insulin levels in $\mathrm{Nw}$ participants. The third factor is medium-chain acylcarnitines profile scores which was higher in Nw subjects than other groups independent to MetS. It was negatively associated with glucose levels among the $\mathrm{Ov} / \mathrm{Ob}$ with MetS. It seems like factor 1 have a relationship effect to deteriorated metabolic profile in obesity, while factor 2 and 3 related to the healthy metabolic profile.(116)

Other interesting metabolites associated with obesity are choline and betaine. They are quaternary ammonium compounds obtained from food or synthesized de novo in tissues. Choline roles as the major source of methyl groups in the diet and can be found in eggs, beef, pork, liver, soybean, and wheat germ. $(117,118)$ Phosphatidylcholine (lecithin) is the most abundant choline species, and an important source of choline relative to dietary intake, moreover in premenopausal women.(119) Lecithin is formed endogenously from phosphatidylethanolamine by a S-adenosylmethionine-dependent methylation reaction catalyzed by phosphatidylethanolamine $\mathrm{N}$-methyltransferase. The biological function of choline, including gene expression epigenetic regulator (120), as a lipoprotein precursor, membrane phospholipids, and the neurotransmitter acetylcholine; thus, it was important for lipid metabolism, the integrity of cell membranes, and nerve function $(117,121)$.

Betaine is a modified amino acid found in the highest content in whole grains such as wheat bran, wheat germ, and spinach. It is also formed in the kidney and liver by choline oxidation catalyzed by the mitochondrial enzyme, choline dehydrogenase.(117,122,123) Betaine is a key organic osmolyte cue to its dipolar zwitterion structure. It accumulates in a variety of cells, including renal medullary cells, under the condition of hypertonicity.(124) Betaine metabolism is dominant in the liver in mammals, where it functions as a methyl donor in the betaine-homocysteine methyltransferase (BHMT) reaction (125), for homocysteine betaine-dependent remethylation yielding dimethylglycine and methionine (126). That's why betaine supplementation can reduce total homocysteine (tHcy) level and they're inversely correlated; therefore betaine used as a treatment for homocysteinemia.(127-130)

Central obesity and excessive flux of fatty acids in the visceral tissue are regarded as the main factors of metabolic syndrome, which leads to insulin resistance and atherogenic dyslipidemia.(131) Betaine intake and plasma levels were inversely correlated with several metabolic syndrome markers.(121,132) Insulin decrease both BHMT and choline dehydrogenase in rat liver, while diabetes increased them (133), human with insulin resistance also found to have lower $\mathrm{N}, \mathrm{N}, \mathrm{N}-$ trimethylglycine, or glycine betaine level. Inversely, betaine decreases hepatic lipid content and improves glucose tolerance in rodents.(134-137) Mitochondrial dysfunction found in metabolic syndrome (138-140), suggests the involvement of choline oxidation to betaine that takes place

Table 1. Compilation of metabolomic profiling studies on obesity patients conducted in various countries.

\begin{tabular}{lcccc}
\hline \multicolumn{1}{c}{ Metabolite } & Sample & Analytical Tools & Country & References \\
\hline Fatty acids pathway & & & & $(108)$ \\
Carnitine (+) & Plasma & LC-MS & USA & $(142)$ \\
Carnitine (-) & Plasma & LC-MS & USA & $(34)$ \\
Acylcarnitine (+) & Plasma and Urine & Flow injection-MS & UK & $(108)$ \\
Acylcarnitine (+) & Plasma & LC-MS & USA & UK \\
\hline Amino acids pathway & & & UK & $(143)$ \\
Leucine (+) & Plasma & LC-MS & South Korea & $(144)$ \\
Valine (+) & Blood and Urine & GC-MS & Italy & $(145)$ \\
Tyrosine (+) & Blood & UPLC-MS & UK & $(143)$ \\
Glutamine (-) & Plasma & LC-MS & UK & $(143)$ \\
Kynurenic acid (-) & Urine & LC-MS & UK & $(143)$ \\
Xanthurenic acid (-) & Urine & LC-MS & & \\
Uric Acid (-) & Plasma & LC-MS & & UK \\
\hline
\end{tabular}


in the inner mitochondrial membrane (139). Thus, choline and betaine dehydrogenase pathways might be associated in insulin resistance, and could be used to predict the response of prevention strategies. Another study showed that dietary betaine increase Fgf21 and improve metabolic health in mice, suggest that betaine supplementation merits further investigation for type 2 diabetes mellitus prevention in humans.(141) Table 1 shows some examples of metabolites profiling on human subjects that have been identified in obesity cases utilizing the metabolomics approaches.

\section{Metabolite Profiles and Risk of Diabetes}

Early identification of functional $\beta$-cell mass will help to prevent diabetes, unfortunately early asymptomatic $\beta$-cell defect identification cannot yet be successfully performed. Metabolomics could be proposed to readout the early disease states before the clinical manifestation by identifying novel plasma biomarkers representing functional pancreatic $\beta$-cell insufficiency before it reaches the clinical symptomatic stage.(146) Recent clinical and laboratory markers can be helpful to indicate the diabetes and its risk progression but provide only a few insight regarding pathophysiologic mechanisms.(147) Nonetheless, identification of individual risk could provide effective interventions for delaying or preventing the onset of T2D and lessen the burden.(148-151)

BCAAs, aromatic amino acids, fructose, mannose, $\alpha$-hydroxybutyrate, and phospholipids are the main metabolites that are consistently appearing in human T2D studies.(106,112,152-158) Most of them are also associated with insulin resistance and obesity $(159,160)$ but not directly to $\beta$-cells alteration. Thus, they still cannot answer the need for biomarkers reflecting the loss of functional $\beta$-cell mass. $(161,162)$

A study documenting the differences in blood metabolite profiles before and after glucose loading in obese vs. lean individuals noted differences in amount of $\mathrm{C} 3$ and $\mathrm{C} 5$ acylcarnitines, glutamine and glutamate, and other small molecules. $(81,83)$ This provides a complementary information to identify at-risk individuals over standard clinical markers.(106) Identification of 1,5-anhydroglucitol showed association with the loss of functional $\beta$-cell mass, raise a possibility of this marker for early detection on $\beta$-cells decline.(163) Another study utilizing LC-MS analyzing amino acids, amines and some polar metabolites, BMI and fasting glucose, found five branched-chain and aromatic amino acids that might significantly predict future diabetes i.e.: isoleucine, leucine, valine, tyrosine and phenylalanine. A combination of three showed more than fivefold higher diabetes risk for individuals in the top quartile, and replicated result has been performed in an independent, prospective cohort. Thus, we can suggest that amino acid profiles could aid in diabetes risk assessment.(112) Additional study in this observed, and a lower ratio of circulating glutamine-toglutamate concentrations (glutamine/glutamate) in Europe population $(84,164)$ proposed for up to 12 years prediction of diabetes in the future.

PGC- $1 \alpha$ is an important protein in human known to regulate energy metabolism. It induces broad genetic programs in skeletal muscles, including mitochondrial biogenesis and fatty acid $\beta$-oxidation. PGC- $1 \alpha$ induces the paracrine activation for angiogenesis, by coordinating a link for fatty acids transport across plasma and mitochondrial membranes, deliver fatty acids to muscle, and also increase trans-endothelial fatty acid transport from the blood vessel lumen to the extraluminal myofibers, which mechanism is not fully understood.

BCAA comprising up to $30 \%$ of muscle protein. Valine is one of BCAAs that is essential in dietary components. In skeletal muscle as well as many other organs, BCAA catabolic flux is tightly regulated. All catabolic products are trapped inside the cell by covalent linkage to coenzyme A, except for 3-hydroxyisobutyrate (3-HIB). Therefore, 3-HIB can be utilized as a secreted reporter of BCAA catabolic flux in muscle. $(106,112,165)$ High 3-HIB secretion from muscle represents the increased catabolic flux of BCAAs, leads to excess trans-endothelial fatty acid import into muscle, accumulate the lipotoxic and incompletely esterified intermediates, such as DAG, finally blunted insulin signaling. Excess BCAA then implicates the progression to diabetes. The levels of 3-HIB in skeletal muscle from $\mathrm{db} / \mathrm{db}$ mice, as well as the muscle biopsies from diabetic patients, were significantly increased. Some studies also reported the increased serum level of 3-HIB in diabetic patients. $(166,167)$ Taken together, paracrine secretion of 3-HIB in the cross-regulatory link between the catabolism of BCAAs and fatty acids, causes excess accumulation of incompletely esterified lipids in skeletal muscle, which finally blunted AKT signaling and glucose intolerance.(168)

Table 2 shows some examples of metabolites profiling on human subjects that have been identified in diabetes cases utilizing the metabolomics approaches. In the past few years, many metabolomic studies were conducted in various countries. Unfortunately, we cannot find a metabolite profiling study from Indonesia performed on human subjects. 
Table 2. Compilation of metabolomic profiling studies on diabetes patients conducted in various countries.

\begin{tabular}{lcccc}
\hline \multicolumn{1}{c}{ Metabolite } & Sample & Analytical Tools & Country & References \\
\hline Fatty acids pathway & & & & \\
Fatty Acids $(+)$ & Serum & GC-MS & China & $(169)$ \\
Fatty Acids (+) & Plasma & LC-MS, GC-MS & Singapore & $(170)$ \\
Carnitine (+) & Plasma & LC-MS & USA & $(108)$ \\
Carnitine (-) & Plasma & LC-MS & USA & $(142)$ \\
Acylcarnitine $(+/-)$ & Plasma & LC-MS & USA & $(171)$ \\
Acylcarnitine $(+)$ & Plasma & LC-MS & USA & $(108)$ \\
$\alpha$-hydroxybutyrate $(+)$ & Plasma & LC-MS, GC-MS & Singapore & $(170)$ \\
3-hydoroxybutyrate $(+)$ & Serum & GC-MS & China & $(169)$ \\
Acetate $(+)$ & Plasma & LC-MS & Germany & $(172)$ \\
\hline Amino acids pathway & & & \\
Leucine $(+)$ & Plasma & UPLC-MS & Germany & $(172)$ \\
Leucine $(+)$ & Serum & NMR, LC-MS, GC-MS & Germany & $(173)$ \\
Isoleucine $(+)$ & Serum & NMR, LC-MS, GC-MS & Germany & $(173)$ \\
Valine $(+)$ & Serum & NMR, LC-MS, GC-MS & Germany & $(173)$ \\
Methionine $(+)$ & Serum & GC-MS & China & $(169)$ \\
Glycine $(-)$ & Serum & LC-MS & Germany & $(174)$ \\
Serine $(+)$ & Plasma & UPLC-MS & Germany & $(172)$ \\
Phenylalanine $(+)$ & Serum & LC-MS & Germany & $(174)$ \\
Phenylalanine $(+)$ & Plasma & LC-MS, GC-MS & Singapore & $(170)$ \\
Glutamate $(-)$ & Serum & GC-MS & China & $(169)$ \\
\hline
\end{tabular}

\section{Pharmacometabolomics and Precision Medicine}

Metabolic disorders occur as a result of dysregulation in multiple biochemical pathways at the molecular level. Disease heterogeneity contributes to drug response variability, and getting more complicated with genetic variability, environment and gut microbiome activity. New approaches were developed to understand drug effects. Pharmacometabolomics and its union with pharmacogenomics provide new insight to discover new biomarkers in clinical pharmacology. $(8,175)$

Recent medical treatment refers to "average patients" based on one-size-fits-all approached therapy, which could be successful for some patients and not for others. On January 2015 "President Obama's Precision Medicine Initiative" released by the White House defines precision medicine as, "a new model of patient-powered research that promises to accelerate biomedical discoveries and provide clinicians with new tools, knowledge, and therapies to select which treatments will work best for which patients." In a simple statement, precision medicine is an individuallytailored treatment based on the patient's illness, given at the right time (Figure 4).(176,177)
The Human Genome Project published a reference for human genome sequence (178) contribute big milestone in biology research, particular in cancer. Metabolomics in the last decade added the understanding of cancer biology. Small molecules studied in metabolomics can be formed by numerous biosynthetic and catabolic pathways within a biological system which present in a cell, tissue, or biofluids such as urine, blood, or saliva, originating from host's microbiota, nutrient, and pharmaceuticals intake to describe a physiological or pathological condition.(179-182) The Human Metabolome Project (HMP) in 2004 equivalent the Human Genome Project, archived 2500 small molecules produced by metabolic reactions in the body's tissues and biofluids (183) include lipids, sugars, ions, metabolic intermediates, and products of biochemical reactions, and also proteins, nucleic acids, and cell membranes as the building blocks for all other biochemical species. Integrating multivariate omics technology including genomics, epigenetics, transcriptomics, proteomics and metabolomics with advanced computation, statistics and bioinformatics will develop mechanistic understanding within molecular biology at the genome, gene transcription, protein and metabolite levels, respectively.(184)

Personalized medicine or precision medicine predict the safest drug treatments for each person, involving 


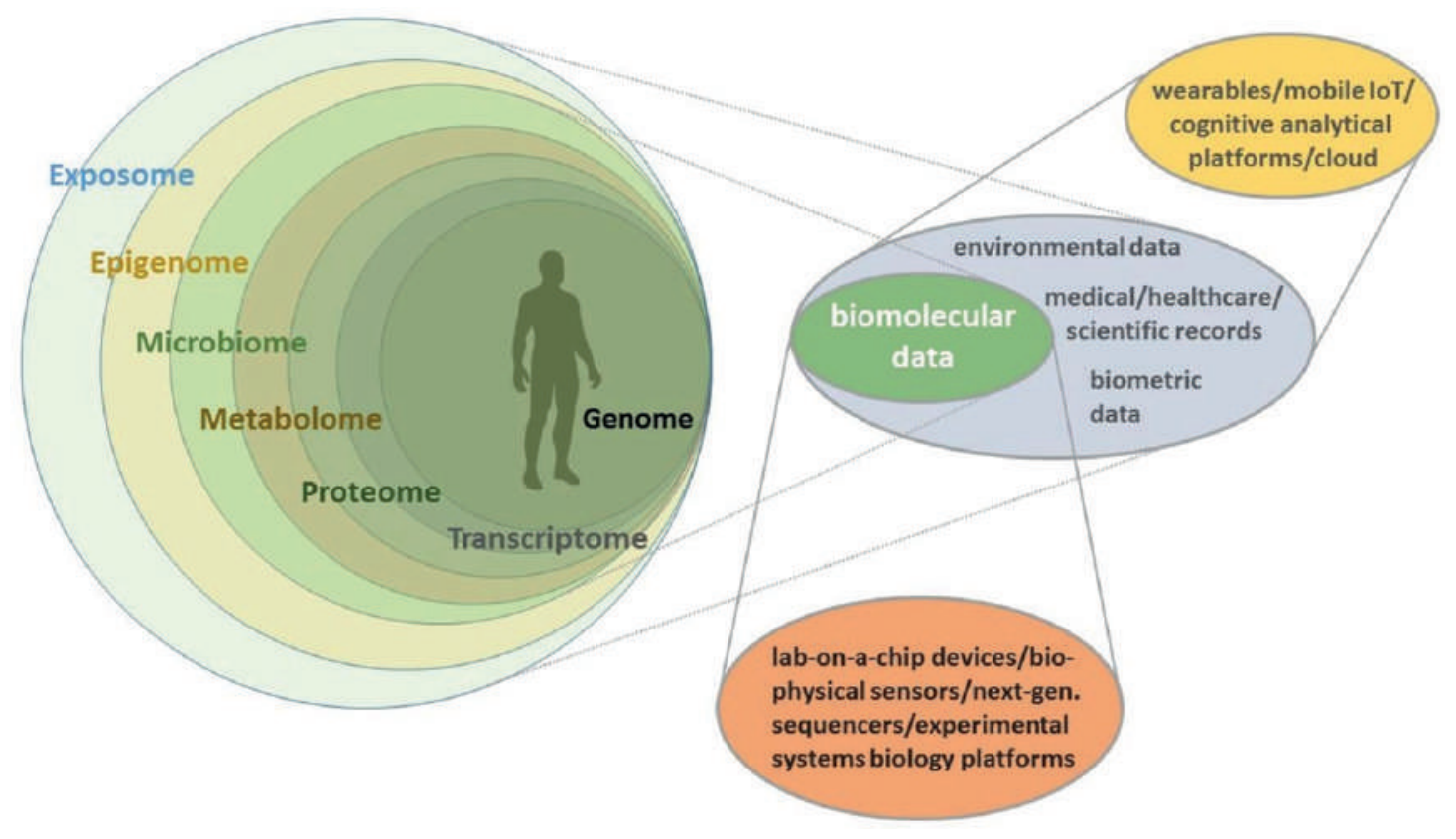

Figure 4. Precision medicine contextualizes data from genome to exposome. Thereby genomic, transcriptomic, proteomic, metabolomic and microbiomic data is biomolecular by nature, while epigenomic and exposomic data also takes environmental, biometric and medical metadata sources into account.(177) (Adapted with permission from SPIE).

individual's genetic, or known as pharmacogenetics and/or pharmacogenomics.(185-189) In fact, many factors more than genetics, such as environmental or some personal factors (i.e., the "exposome"), alcohol consumption, the gut microbiome, nutrients intake, another medications and supplements, age, and other comorbidities (such as obesity, cancer, pregnancy) make the clinical implementation of pharmacogenomic face lots of challenges.(190-192) The determination of individual metabolic state refer as "metabotype" (7,193-196) could be employed to define someone's metabolic signatures and provide a better prediction of the potential for drug safety issues (197-199), together this fields called as pharmacometabolomics (6) and pharmacometabonomics (193).

Pharmacogenomics classify patients as poor or rapid drug metabolizers, or responder and non-responder. $(186,200,201)$ However, patient's genotype does not always have a clear definition of the phenotype or the current (patho) physiological state of the individual (190), because the genotype cannot describe the environmental factors and/or disease-related factors influence. Phenotypic status of an individual results from complex factors such as demographic, environmental interaction, gut microbiota, and any comorbidities, then the endogenous metabolite profile describes a snapshot of these all. Metabolomics application provides a direct readout of individual current state, so it can better explain the inter-individual variability of drug pharmacokinetic and pharmacodynamic. Pharmacometabolomics evaluate the metabolism of pharmaceutical compounds of the patients, and better understand the pharmacokinetic profile of a drug (Figure 5). Study of pharmacometabolomics involving the application of pharmacology, includes pharmacokinetics to define metabolic influences on the drug concentration reaching its target, pharmacodynamics to define metabolic influences on target signaling downstream, clinical pharmacology, drug discovery and development, clinical trials and precision medicine. The application of "metabotypes" sub-classified patients based on their metabolic profiles and useful for grouping the subjects in trial inclusion $(8,202,203)$. When we interplay this baseline to pharmacometabolomic, we

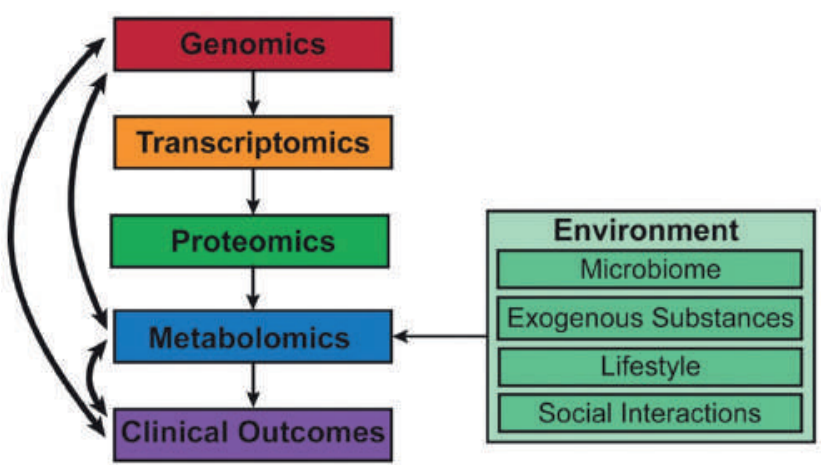

Figure 5. Pharmacometabolomics-informed pharmacogenomics.(202) (Adapted from permission from PMC). 


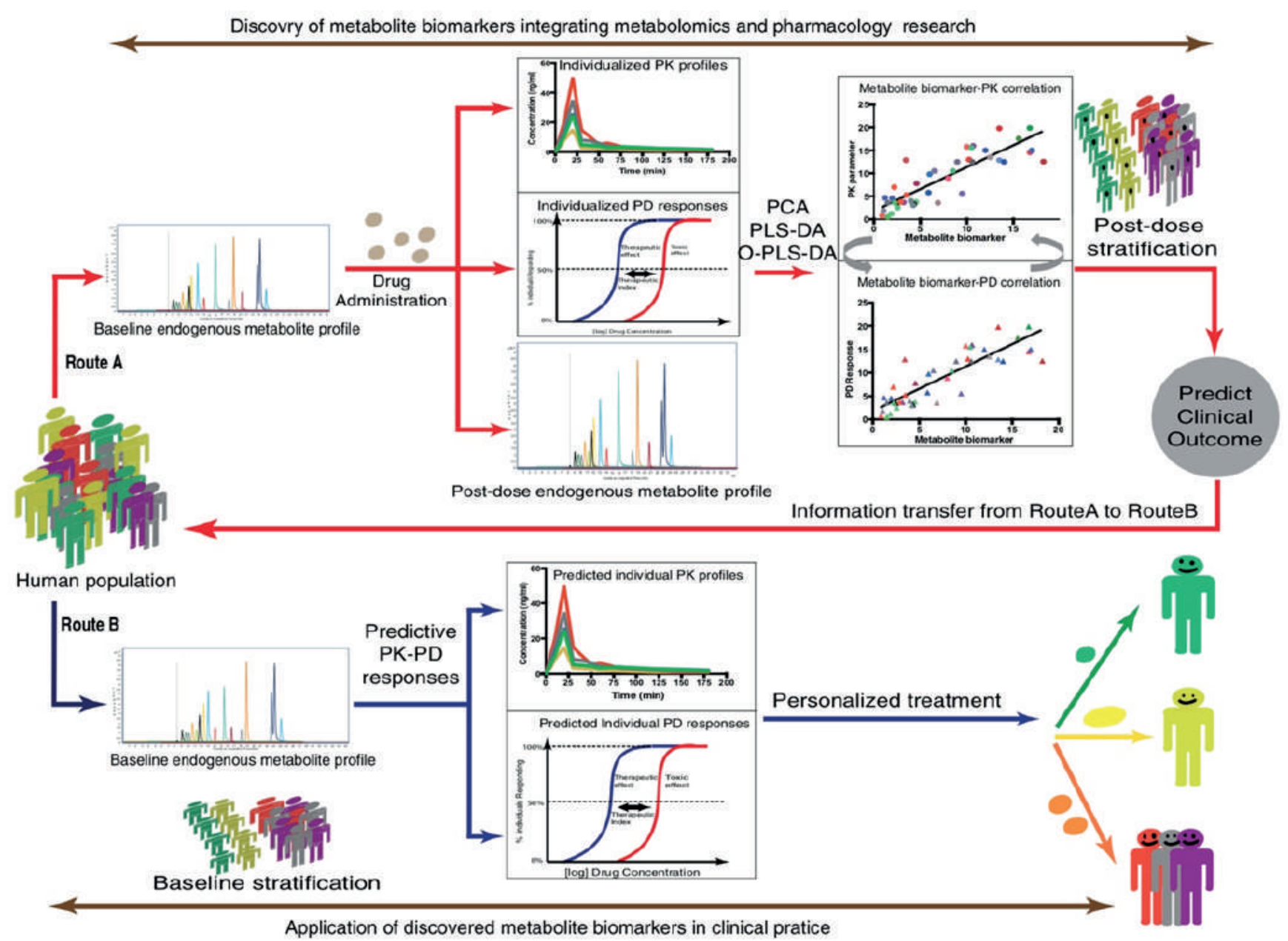

Figure 6. Pharmacometabolomics in research (route A) and clinical practice (route B).(206) (Adapted with permission from Springer).

can better define mechanisms of pharmacodynamic and pharmacokinetic variation between individual in response to drug therapy by measuring endogenous metabolites. (204-209) Figure 6 shows how pharmacometabolomics in research and in clinical practice works.

In humans and most complex systems, interdependent changes in the gene, protein and metabolite levels can occur on very different time scales. These become more complicated because an intestinal system has an internal ecosystem where the host interacting with many species of gut microbial organisms (210-212), and also the impact of environmental factors making the individual "metabotype" individual is highly responsive to time and the environment. (213) Metabolomic studies can be utilized to examine and understand this changes (214-218) and improve the therapies selection for particular patient classes, at once assess the drugs' efficacy and toxic side effects.(184,218) it can be proposed from recent studies to create a patient metabolic phenotyping, together with the prognosis and pre- treatment metabolic information to predict post-treatment outcomes and refine the strategy for personalized medicine $(4,213)$.

Metabolomics give a better understanding about the metabolic signatures of diseases and then will provide predictive, prognostic, diagnostic, and surrogate markers of diverse disease states; expand our understanding on underlying molecular mechanisms of diseases; allow for stratification of patients based on metabolic pathways impacted; reveal biomarkers for drug response phenotypes, so we can predict the variation in a subject's response to treatment (pharmacometabolomics) effectively; define a metabotype for each specific genotype, offering a functional readout for genetic variants: allow us to monitor response and recurrence of diseases; and describe the molecular landscape in human performance applications and extreme environments. Overall, this will change the way we treat diseases and find out the optimal therapeutic regiment precisely for each individual.(1) 


\section{Conclusion}

Metabolome give important opportunities at present to revolutionize the strategy of precision medicine. Metabolomics is potential to be a key profile and phenotyping platform to predict patients' responses to different treatments. Equipped with other omics methodologies, metabolomic develop a decision support tool for selecting or recommending optimal treatment regimens and lifestyle changes. The goal is by using the personalized profiles to enhance the therapy effectivity and contribute to better patient outcomes. An integrated omics platform in the future will take account to complement the next-generation healthcare system, and there is a need to develop the methods for absolute quantification of metabolites, miniaturized metabolomics instruments, enhancing the automated data processing, to boost the translation of metabolomics either in new biomarkers discovery or in pharmacometabolomics.

\section{Authors Contribution}

AM planned, drafted and wrote the manuscript, NMD edited the manuscript and tables, while AW provided the main idea of the manuscript and proof read the final manuscript.

\section{References}

1. Beger RD, Dunn W, Schmidt MA, Gross SS, Kirwan JA, Cascante M, et al. Metabolomics enables precision medicine: "A White Paper, Community Perspective." Metabolomics Off J Metabolomic Soc. 2016; 12:149. doi: 10.1007/s11306-016-1094-6.

2. Clish CB. Metabolomics: an emerging but powerful tool for precision medicine. Cold Spring Harb Mol Case Stud. 2015; 1: a000588. doi: 10.1101/mcs.a000588

3. Beger RD, Bhattacharyya S, Yang X, Gill PS, Schnackenberg LK, Sun J, et al. Translational biomarkers of acetaminophen-induced acute liver injury. Arch Toxicol. 2015; 89: 1497-522.

4. Cacciatore S, Loda M. Innovation in metabolomics to improve personalized healthcare. Ann NY Acad Sci. 2015; 1346: 57-62.

5. Everett JR. Pharmacometabonomics in humans: a new tool for personalized medicine. Pharmacogenomics. 2015; 16: 737-54.

6. Kaddurah-Daouk R, Kristal BS, Weinshilboum RM. Metabolomics: a global biochemical approach to drug response and disease. Annu Rev Pharmacol Toxicol. 2008; 48: 653-83.

7. Kaddurah-Daouk R, Weinshilboum RM, Pharmacometabolomics Research Network. Pharmacometabolomics: implications for clinical pharmacology and systems pharmacology. Clin Pharmacol Ther. 2014; 95: 154-67.
8. Kaddurah-Daouk R, Weinshilboum R, Pharmacometabolomics Research Network. Metabolomic signatures for drug response phenotypes: pharmacometabolomics enables precision medicine. Clin Pharmacol Ther. 2015; 98: 71-5.

9. Kastenmüller G, Raffler J, Gieger C, Suhre K. Genetics of human metabolism: an update. Hum Mol Genet. 2015; 24: R93-101.

10. Nicholson JK, Everett JR, Lindon JC. Longitudinal pharmacometabonomics for predicting patient responses to therapy: drug metabolism, toxicity and efficacy. Expert Opin Drug Metab Toxicol. 2012; 8: 135-9.

11. Patti GJ, Yanes O, Siuzdak G. Metabolomics: the apogee of the omic triology. Nat Rev Mol Cell Biol. 2012; 13: 263-9.

12. Su LJ, Fiehn O, Maruvada P, Moore SC, O'Keefe SJ, Wishart DS, et al. The use of metabolomics in population-based research123. Adv Nutr. 2014; 5: 785-8.

13. Suhre K, Raffler J, Kastenmüller G. Biochemical insights from population studies with genetics and metabolomics. Arch Biochem Biophys. 2016; 589: 168-76.

14. Wilson ID. Drugs, bugs, and personalized medicine: pharmacometabonomics enters the ring. Proc Natl Acad Sci USA. 2009; 106: 14187-8.

15. Zamboni N, Saghatelian A, Patti GJ. Defining the metabolome: size, flux, and regulation. Mol Cell. 2015; 58: 699-706.

16. Pinu FR, Goldansaz SA, Jaine J. Translational metabolomics: current challenges and future opportunities. Metabolites. 2019; 9: 108. doi: 10.3390/metabo9060108

17. Roessner U, Bowne J. What is metabolomics all about? BioTechniques. 2009; 46: 363-5.

18. Wishart DS, Knox C, Guo AC, Eisner R, Young N, Gautam B, et al. HMDB: a knowledgebase for the human metabolome. Nucleic Acids Res. 2009; 37: D603-10.

19. Spratlin JL, Serkova NJ, Eckhardt SG. Clinical applications of metabolomics in oncology: a review. Clin Cancer Res Off J Am Assoc Cancer Res. 2009; 15: 431-40.

20. Lindon JC, Nicholson JK. Analytical technologies for metabonomics and metabolomics, and multi-omic information recovery. TrAC Trends Anal Chem. 2008; 27: 194-204.

21. Wishart DS, Tzur D, Knox C, Eisner R, Guo AC, Young N, et al. HMDB: the Human Metabolome Database. Nucleic Acids Res. 2007; 35: D521-6.

22. van der Greef J, van Wietmarschen H, van Ommen B, Verheij E. Looking back into the future: 30 years of metabolomics at TNO. Mass Spectrom Rev. 2013; 32: 399-415.

23. He JC, Chuang PY, Ma'ayan A, Iyengar R. Systems biology of kidney diseases. Kidney Int. 2012; 81: 22-39.

24. Weiss RH, Kim K. Metabolomics in the study of kidney diseases. Nat Rev Nephrol. 2011; 8: 22-33.

25. Gomase VS, Changbhale SS, Patil SA, Kale KV. Metabolomics. Curr Drug Metab. 2008; 9: 89-98

26. Rochfort S. Metabolomics reviewed: a new "omics" platform technology for systems biology and implications for natural products research. J Nat Prod. 2005; 68: 1813-20.

27. Edelstein CL. Biomarkers of Kidney Disease. 2nd Ed. Cambridge: Academic Press; 2017

28. Ryan D, Robards K. Metabolomics: the greatest omics of them all? Anal Chem. 2006; 78: 7954-8.

29. Griffiths WJ, Koal T, Wang Y, Kohl M, Enot DP, Deigner HP. Targeted metabolomics for biomarker discovery. Angew Chem Int Ed Engl. 2010; 49: 5426-45

30. Goodacre R, Vaidyanathan S, Dunn WB, Harrigan GG, Kell DB. Metabolomics by numbers: acquiring and understanding global metabolite data. Trends Biotechnol. 2004; 22: 245-52. 
31. Rattray NJW, Daouk RK. Pharmacometabolomics and precision medicine special issue editorial. Metabolomics. 2017; 13: 59. doi: 10.1007/s11306-017-1191-1.

32. Trivedi DK, Hollywood KA, Goodacre R. Metabolomics for the masses: The future of metabolomics in a personalized world. New Horiz Transl Med. 2017; 3: 294-305.

33. Dunn WB, Lin W, Broadhurst D, Begley P, Brown M, Zelena E, et al. Molecular phenotyping of a UK population: defining the human serum metabolome. Metabolomics Off J Metabolomic Soc. 2015; 11: 9-26.

34. Newgard CB, An J, Bain JR, Muehlbauer MJ, Stevens RD, Lien LF, et al. A branched-chain amino acid-related metabolic signature that differentiates obese and lean humans and contributes to insulin resistance. Cell Metab. 2009; 9: 311-26.

35. Koeth RA, Wang Z, Levison BS, Buffa JA, Org E, Sheehy BT, et al. Intestinal microbiota metabolism of L-carnitine, a nutrient in red meat, promotes atherosclerosis. Nat Med. 2013; 19: 576-85.

36. Draisma HHM, Pool R, Kobl M, Jansen R, Petersen AK, Vaarhorst $\mathrm{AAM}$, et al. Genome-wide association study identifies novel genetic variants contributing to variation in blood metabolite levels. Nat Commun. 2015; 6: 7208. doi: 10.1038/ncomms8208.

37. Dunn WB, Bailey NJC, Johnson HE. Measuring the metabolome: current analytical technologies. The Analyst. 2005; 130: 606-25.

38. Wishart DS, Jewison T, Guo AC, Wilson M, Knox C, Liu Y, et al. HMDB 3.0--The Human Metabolome Database in 2013. Nucleic Acids Res. 2013; 41: D801-7.

39. Manach C, Hubert J, Llorach R, Scalbert A. The complex links between dietary phytochemicals and human health deciphered by metabolomics. Mol Nutr Food Res. 2009; 53: 1303-15.

40. Johnson CH, Patterson AD, Idle JR, Gonzalez FJ. Xenobiotic metabolomics: major impact on the metabolome. Annu Rev Pharmacol Toxicol. 2012; 52: 37-56.

41. Mapstone M, Cheema AK, Fiandaca MS, Zhong X, Mhyre TR, MacArthur LH, et al. Plasma phospholipids identify antecedent memory impairment in older adults. Nat Med. 2014; 20: 415-8.

42. German JB, Hammock BD, Watkins SM. Metabolomics: building on a century of biochemistry to guide human health. Metabolomics Off J Metabolomic Soc. 2005; 1: 3-9.

43. Cascante M, Marin S. Metabolomics and fluxomics approaches. Essays Biochem. 2008; 45: 67-82.

44. Rhee EP, Cheng S, Larson MG, Walford GA, Lewis GD, McCabe E, et al. Lipid profiling identifies a triacylglycerol signature of insulin resistance and improves diabetes prediction in humans. J Clin Invest. 2011; 121: 1402-11.

45. Monteiro MS, Carvalho M, Bastos ML, Guedes de Pinho P. Metabolomics analysis for biomarker discovery: advances and challenges. Curr Med Chem. 2013; 20: 257-71.

46. Nordström A, Lewensohn R. Metabolomics: moving to the clinic. J Neuroimmune Pharmacol Off J Soc NeuroImmune Pharmacol. 2010; 5: 4-17.

47. Mamas M, Dunn WB, Neyses L, Goodacre R. The role of metabolites and metabolomics in clinically applicable biomarkers of disease. Arch Toxicol. 2011; 85: 5-17.

48. Wang TJ, Ngo D, Psychogios N, Dejam A, Larson MG, Vasan RS, et al. 2-Aminoadipic acid is a biomarker for diabetes risk. J Clin Invest. 2013; 123: 4309-17.

49. Wei R, Li G, Seymour AB. Multiplexed, quantitative, and targeted metabolite profiling by LC-MS/MRM. Methods Mol Biol Clifton NJ. 2014; 1198: 171-99.

50. Altadill T, Campoy I, Lanau L, Gill K, Rigau M, Gil-Moreno A, et al. Enabling metabolomics based biomarker discovery studies using molecular phenotyping of exosome-like vesicles. PloS One. 2016;
11: e0151339. doi: 10.1371/journal.pone.0151339.

51. Brennan L. Metabolomics in nutrition research: current status and perspectives. Biochem Soc Trans. 2013; 41: 670-3.

52. Madsen R, Lundstedt T, Trygg J. Chemometrics in metabolomics--a review in human disease diagnosis. Anal Chim Acta. 2010 Feb; 659: 23-33.

53. Erazo M, Garcýa A, Ruperez F, Barbaz C. Metabolomics of dietrelated diseases. In: Cifuentes A, editor. Foodomics: Advanced Mass Spectrometry in Modern Food Science and Nutrition. Hoboken: John Wiley \& Sons; 2013. p. 429-51.

54. Bingham SA. Biomarkers in nutritional epidemiology. Public Health Nutr. 2002; 5: 821-7.

55. Kipnis V, Midthune D, Freedman L, Bingham S, Day NE, Riboli $\mathrm{E}$, et al. Bias in dietary-report instruments and its implications for nutritional epidemiology. Public Health Nutr. 2002; 5: 915-23.

56. Tasevska N, Runswick SA, McTaggart A, Bingham SA. Urinary sucrose and fructose as biomarkers for sugar consumption. Cancer Epidemiol Biomark Prev Publ Am Assoc Cancer Res Cosponsored Am Soc Prev Oncol. 2005; 14: 1287-94.

57. Freedman LS, Kipnis V, Schatzkin A, Tasevska N, Potischman N. Can we use biomarkers in combination with self-reports to strengthen the analysis of nutritional epidemiologic studies? Epidemiol Perspect Innov EPI. 2010; 7: 2. doi: 10.1186/1742-5573-7-2.

58. Armitage EG, Rupérez FJ, Barbas C. Metabolomics of diet-related diseases using mass spectrometry. TrAC Trends Anal Chem. 2013; 52: 61-73.

59. Dagogo-Jack S. Metabolomic prediction of diabetes and cardiovascular risk. Med Princ Pract. 2012; 21: 401-3.

60. Kim SA, Kim JY, Yun EJ, Kim KH. Food metabolomics: from farm to human. Curr Opin Biotechnol. 2016; 37: 16-23.

61. Monteiro CA, Levy RB, Claro RM, Castro IRR de, Cannon G. A new classification of foods based on the extent and purpose of their processing. Cad Saude Publica. 2010; 26: 2039-49.

62. Liu H, Tayyari F, Khoo C, Gu L. A 1H NMR-based approach to investigate metabolomic differences in the plasma and urine of young women after cranberry juice or apple juice consumption. J Funct Foods. 2015; 14: 76-86.

63. Pujos-Guillot E, Hubert J, Martin JF, Lyan B, Quintana M, Claude S, et al. Mass spectrometry-based metabolomics for the discovery of biomarkers of fruit and vegetable intake: citrus fruit as a case study. J Proteome Res. 2013; 12: 1645-59.

64. Hanhineva K, Lankinen MA, Pedret A, Schwab U, Kolehmainen M, Paananen J, et al. Nontargeted metabolite profiling discriminates diet-specific biomarkers for consumption of whole grains, fatty fish, and bilberries in a randomized controlled trial. J Nutr. 2015; 145: 7-17.

65. Urpi-Sarda M, Boto-Ordóñez M, Queipo-Ortuño MI, Tulipani $\mathrm{S}$, Corella D, Estruch R, et al. Phenolic and microbial-targeted metabolomics to discovering and evaluating wine intake biomarkers in human urine and plasma. Electrophoresis. 2015; 36: 2259-68.

66. Rothwell JA, Fillâtre Y, Martin JF, Lyan B, Pujos-Guillot E, Fezeu L, et al. New biomarkers of coffee consumption identified by the nontargeted metabolomic profiling of cohort study subjects. PloS One. 2014; 9: e93474. doi: 10.1371/journal.pone.0093474.

67. Bouchard-Mercier A, Rudkowska I, Lemieux S, Couture P, Vohl MC. The metabolic signature associated with the Western dietary pattern: a cross-sectional study. Nutr J. 2013; 12: 158. doi: 10.1186/14752891-12-158.

68. O’Sullivan A, Gibney MJ, Brennan L. Dietary intake patterns are reflected in metabolomic profiles: potential role in dietary assessment studies. Am J Clin Nutr. 2011; 93: 314-21. 
69. Brennan L. Session 2: Personalised nutrition metabolomic applications in nutritional research: Symposium on 'The challenge of translating nutrition research into public health nutrition.' Proc Nutr Soc. 2008; 67: 404-8.

70. Menni C, Zhai G, Macgregor A, Prehn C, Römisch-Margl W, Suhre $\mathrm{K}$, et al. Targeted metabolomics profiles are strongly correlated with nutritional patterns in women. Metabolomics Off J Metabolomic Soc. 2013; 9: 506-14.

71. Newby PK, Tucker KL. Empirically derived eating patterns using factor or cluster analysis: a review. Nutr Rev. 2004; 62: 177-203.

72. Bhupathiraju SN, Tucker KL. Coronary heart disease prevention: nutrients, foods, and dietary patterns. Clin Chim Acta Int J Clin Chem. 2011; 412: 1493-514

73. Yusof AS, Isa ZM, Shah SA. Dietary patterns and risk of colorectal cancer: a systematic review of cohort studies (2000-2011). Asian Pac J Cancer Prev APJCP. 2012; 13: 4713-7.

74. Esmaillzadeh A, Kimiagar M, Mehrabi Y, Azadbakht L, Hu FB, Willett WC. Dietary patterns, insulin resistance, and prevalence of the metabolic syndrome in women. Am J Clin Nutr. 2007; 85: 910-8.

75. Schulze MB, Hoffmann K, Manson JE, Willett WC, Meigs JB, Weikert $\mathrm{C}$, et al. Dietary pattern, inflammation, and incidence of type 2 diabetes in women. Am J Clin Nutr. 2005; 82: 675-84.

76. Allen J, Davey HM, Broadhurst D, Heald JK, Rowland JJ, Oliver SG, et al. High-throughput classification of yeast mutants for functional genomics using metabolic footprinting. Nat Biotechnol. 2003; 21: 692-6.

77. An J, Muoio DM, Shiota M, Fujimoto Y, Cline GW, Shulman GI, et al. Hepatic expression of malonyl-CoA decarboxylase reverses muscle, liver and whole-animal insulin resistance. Nat Med. 2004; 10: $268-74$.

78. Nicholson JK, Wilson ID. Opinion: understanding "global" systems biology: metabonomics and the continuum of metabolism. Nat Rev Drug Discov. 2003; 2: 668-76.

79. Raamsdonk LM, Teusink B, Broadhurst D, Zhang N, Hayes A, Walsh $\mathrm{MC}$, et al. A functional genomics strategy that uses metabolome data to reveal the phenotype of silent mutations. Nat Biotechnol. 2001; 19: 45-50.

80. Holmes E, Loo RL, Stamler J, Bictash M, Yap IKS, Chan Q, et al. Human metabolic phenotype diversity and its association with diet and blood pressure. Nature. 2008; 453: 396-400.

81. Shaham O, Wei R, Wang TJ, Ricciardi C, Lewis GD, Vasan RS, et al. Metabolic profiling of the human response to a glucose challenge reveals distinct axes of insulin sensitivity. Mol Syst Biol. 2008; 4: 214. doi: $10.1038 / \mathrm{msb} .2008 .50$.

82. Wopereis S, Rubingh CM, Erk MJ van, Verheij ER, Vliet T van, Cnubben NHP, et al. Metabolic profiling of the response to an oral glucose tolerance test detects subtle metabolic changes. PloS One. 2009; 4: e4525. doi: 10.1371/journal.pone.0004525.

83. Zhao X, Peter A, Fritsche J, Elcnerova M, Fritsche A, Häring HU, et al. Changes of the plasma metabolome during an oral glucose tolerance test: is there more than glucose to look at? Am J Physiol Endocrinol Metab. 2009; 296: E384-93.

84. Cheng S, Rhee EP, Larson MG, Lewis GD, McCabe EL, Shen D, et al. Metabolite profiling identifies pathways associated with metabolic risk in humans. Circulation. 2012; 125: 2222-31.

85. Dietary Guidelines Advisory Committee. Scientific Report of the 2015 Dietary Guidelines Advisory Committee. Maryland: U.S. Department of Agriculture, Agricultural Research Service; 2015.

86. Liu X, Wang X, Lin S, Yuan J, Yu ITS. Dietary patterns and oesophageal squamous cell carcinoma: a systematic review and meta-analysis. Br J Cancer. 2014; 110: 2785-95.
87. Reedy J, Wirfält E, Flood A, Mitrou PN, Krebs-Smith SM, Kipnis V, et al. Comparing 3 dietary pattern methods--cluster analysis, factor analysis, and index analysis--With colorectal cancer risk: The NIHAARP Diet and Health Study. Am J Epidemiol. 2010; 171: 479-87.

88. George SM, Ballard-Barbash R, Manson JE, Reedy J, Shikany JM, Subar AF, et al. Comparing indices of diet quality with chronic disease mortality risk in postmenopausal women in the Women's Health Initiative Observational Study: evidence to inform national dietary guidance. Am J Epidemiol. 2014; 180: 616-25.

89. Reedy J, Krebs-Smith SM, Miller PE, Liese AD, Kahle LL, Park Y, et $a l$. Higher diet quality is associated with decreased risk of all-cause, cardiovascular disease, and cancer mortality among older adults. J Nutr. 2014; 144: 881-9.

90. Slattery ML. Defining dietary consumption: is the sum greater than its parts? Am J Clin Nutr. 2008; 88: 14-5.

91. Guenther PM, Kirkpatrick SI, Reedy J, Krebs-Smith SM, Buckman DW, Dodd KW, et al. The Healthy Eating Index-2010 is a valid and reliable measure of diet quality according to the 2010 Dietary Guidelines for Americans. J Nutr. 2014; 144: 399-407.

92. NEL. A series of systematic reviews on the relationship between dietary patterns and health outcomes. Alexandria: US Department of Agriculture, Center for Nutrition Policy and Promotion; 2014.

93. Jenab M, Slimani N, Bictash M, Ferrari P, Bingham SA. Biomarkers in nutritional epidemiology: applications, needs and new horizons. Hum Genet. 2009; 125: 507-25.

94. Wishart DS. Metabolomics: applications to food science and nutrition research. Trends Food Sci Technol. 2008; 19: 482-93.

95. Scalbert A, Brennan L, Fiehn O, Hankemeier T, Kristal BS, van Ommen B, et al. Mass-spectrometry-based metabolomics: limitations and recommendations for future progress with particular focus on nutrition research. Metabolomics Off J Metabolomic Soc. 2009; 5: 435-58.

96. Heinzmann SS, Brown IJ, Chan Q, Bictash M, Dumas ME, Kochhar $\mathrm{S}$, et al. Metabolic profiling strategy for discovery of nutritional biomarkers: proline betaine as a marker of citrus consumption. Am J Clin Nutr. 2010; 92: 436-43.

97. Evans AM, Bridgewater BR, Liu Q, Mitchell MW, Robinson RJ, Dai $\mathrm{H}$, et al. High resolution mass spectrometry improves data quantity and quality as compared to unit mass resolution mass spectrometry in high-throughput profiling metabolomics. J Postgenomics Drug Biomark Dev. 2014; 4: 1000132. doi: 10.4172/2153-0769.1000132.

98. Playdon MC, Moore SC, Derkach A, Reedy J, Subar AF, Sampson $\mathrm{JN}$, et al. Identifying biomarkers of dietary patterns by using metabolomics. Am J Clin Nutr. 2017; 105: 450-65.

99. Floegel A, Drogan D, Wang-Sattler R, Prehn C, Illig T, Adamski J, et $a l$. Reliability of serum metabolite concentrations over a 4-month period using a targeted metabolomic approach. PloS One. 2011; 6: e21103. doi: 10.1371/journal.pone.0021103.

100. Mokdad AH, Serdula MK, Dietz WH, Bowman BA, Marks JS, Koplan JP. The spread of the obesity epidemic in the United States, 1991-1998. JAMA. 1999; 282: 1519-22.

101. Aguilar-Salinas CA, García EG, Robles L, Riaño D, Ruiz-Gomez DG, García-Ulloa AC, et al. High adiponectin concentrations are associated with the metabolically healthy obese phenotype. J Clin Endocrinol Metab. 2008; 93: 4075-9.

102. Wildman RP, Muntner P, Reynolds K, McGinn AP, Rajpathak S, Wylie-Rosett J, et al. The obese without cardiometabolic risk factor clustering and the normal weight with cardiometabolic risk factor clustering: prevalence and correlates of 2 phenotypes among the US population (NHANES 1999-2004). Arch Intern Med. 2008; 168: 1617-24. 
103. Hamer M, Stamatakis E. Metabolically healthy obesity and risk of all-cause and cardiovascular disease mortality. J Clin Endocrinol Metab. 2012; 97: 2482-8.

104. Appleton SL, Seaborn CJ, Visvanathan R, Hill CL, Gill TK, Taylor $\mathrm{AW}$, et al. Diabetes and cardiovascular disease outcomes in the metabolically healthy obese phenotype: a cohort study. Diabetes Care. 2013; 36: 2388-94.

105. Chen HH, Tseng YJ, Wang SY, Tsai YS, Chang CS, Kuo TC, et al. The metabolome profiling and pathway analysis in metabolic healthy and abnormal obesity. Int J Obes 2005. 2015; 39: 1241-8.

106. Kuehnbaum NL, Britz-McKibbin P. New advances in separation science for metabolomics: resolving chemical diversity in a postgenomic era. Chem Rev. 2013; 113: 2437-68.

107. Kochhar S, Jacobs DM, Ramadan Z, Berruex F, Fuerholz A, Fay LB. Probing gender-specific metabolism differences in humans by nuclear magnetic resonance-based metabonomics. Anal Biochem. 2006; 352: 274-81.

108. Mihalik SJ, Goodpaster BH, Kelley DE, Chace DH, Vockley J, Toledo FGS, et al. Increased levels of plasma acylcarnitines in obesity and type 2 diabetes and identification of a marker of glucolipotoxicity. Obes Silver Spring Md. 2010; 18: 1695-700.

109. Oberbach A, Blüher M, Wirth H, Till H, Kovacs P, Kullnick Y, et al. Combined proteomic and metabolomic profiling of serum reveals association of the complement system with obesity and identifies novel markers of body fat mass changes. J Proteome Res. 2011; 10 : 4769-88.

110. Tai ES, Tan MLS, Stevens RD, Low YL, Muehlbauer MJ, Goh DLM, et al. Insulin resistance is associated with a metabolic profile of altered protein metabolism in Chinese and Asian-Indian men. Diabetologia. 2010; 53: 757-67.

111. Huffman KM, Shah SH, Stevens RD, Bain JR, Muehlbauer M, Slentz CA, et al. Relationships between circulating metabolic intermediates and insulin action in overweight to obese, inactive men and women. Diabetes Care. 2009; 32: 1678-83.

112. van der Greef J, Stroobant P, van der Heijden R. The role of analytical sciences in medical systems biology. Curr Opin Chem Biol. 2004; 8: 559-65.

113. McCormack SE, Shaham O, McCarthy MA, Deik AA, Wang TJ, Gerszten RE, et al. Circulating branched-chain amino acid concentrations are associated with obesity and future insulin resistance in children and adolescents. Pediatr Obes. 2013; 8: 52-61.

114. Perng W, Gillman MW, Fleisch AF, Michalek RD, Watkins SM, Isganaitis E, et al. Metabolomic profiles and childhood obesity. Obes Silver Spring Md. 2014; 22: 2570-8.

115. Bain JR, Stevens RD, Wenner BR, Ilkayeva O, Muoio DM, Newgard CB. Metabolomics applied to diabetes research: moving from information to knowledge. Diabetes. 2009; 58: 2429-43.

116. Allam-Ndoul B, Guénard F, Garneau V, Cormier H, Barbier O, Pérusse L, et al. Association between metabolite profiles, metabolic syndrome and obesity status. Nutrients. 2016; 8: 324. doi: 10.3390/ nu8060324.

117. Zeisel SH, Blusztajn JK. Choline and human nutrition. Annu Rev Nutr. 1994; 14: 269-96.

118. Zeisel SH, Mar MH, Howe JC, Holden JM. Concentrations of cholinecontaining compounds and betaine in common foods. J Nutr. 2003; 133: 1302-7.

119. Zeisel SH. Choline: critical role during fetal development and dietary requirements in adults. Annu Rev Nutr. 2006; 26: 229-50.

120. Niculescu MD, Craciunescu CN, Zeisel SH. Dietary choline deficiency alters global and gene-specific DNA methylation in the developing hippocampus of mouse fetal brains. FASEB J Off Publ Fed Am Soc Exp Biol. 2006; 20: 43-9.
121. Konstantinova SV, Tell GS, Vollset SE, Nygård O, Bleie Ø, Ueland PM. Divergent associations of plasma choline and betaine with components of metabolic syndrome in middle age and elderly men and women. J Nutr. 2008; 138: 914-20.

122. Chern MK, Pietruszko R. Evidence for mitochondrial localization of betaine aldehyde dehydrogenase in rat liver: purification, characterization, and comparison with human cytoplasmic E3 isozyme. Biochem Cell Biol Biochim Biol Cell. 1999; 77: 179-87.

123. Craig SAS. Betaine in human nutrition. Am J Clin Nutr. 2004; 80: 539-49.

124. Delgado-Reyes CV, Garrow TA. High sodium chloride intake decreases betaine-homocysteine S-methyltransferase expression in guinea pig liver and kidney. Am J Physiol Regul Integr Comp Physiol. 2005; 288: R182-7.

125. Ueland PM, Holm PI, Hustad S. Betaine: a key modulator of onecarbon metabolism and homocysteine status. Clin Chem Lab Med. 2005; 43: 1069-75.

126. Mato JM, Martínez-Chantar ML, Lu SC. Methionine metabolism and liver disease. Annu Rev Nutr. 2008; 28: 273-93.

127. Olthof MR, Verhoef P. Effects of betaine intake on plasma homocysteine concentrations and consequences for health. Curr Drug Metab. 2005; 6: 15-22.

128. Holm PI, Bleie Ø, Ueland PM, Lien EA, Refsum H, Nordrehaug $\mathrm{JE}$, et al. Betaine as a determinant of postmethionine load total plasma homocysteine before and after B-vitamin supplementation. Arterioscler Thromb Vasc Biol. 2004; 24: 301-7.

129. Holm PI, Hustad S, Ueland PM, Vollset SE, Grotmol T, Schneede J. Modulation of the homocysteine-betaine relationship by methylenetetrahydrofolate reductase $677 \mathrm{C}->\mathrm{t}$ genotypes and B-vitamin status in a large-scale epidemiological study. J Clin Endocrinol Metab. 2007; 92: 1535-41.

130. Graham IM, Daly LE, Refsum HM, Robinson K, Brattström LE, Ueland PM, et al. Plasma homocysteine as a risk factor for vascular disease: The European Concerted Action Project. JAMA. 1997; 277: 1775-81.

131. Eckel RH, Grundy SM, Zimmet PZ. The metabolic syndrome. Lancet Lond Engl. 2005; 365: 1415-28.

132. Detopoulou P, Panagiotakos DB, Antonopoulou S, Pitsavos C, Stefanadis C. Dietary choline and betaine intakes in relation to concentrations of inflammatory markers in healthy adults: the ATTICA study. Am J Clin Nutr. 2008; 87: 424-30.

133. Ratnam S, Wijekoon EP, Hall B, Garrow TA, Brosnan ME, Brosnan JT. Effects of diabetes and insulin on betaine-homocysteine S-methyltransferase expression in rat liver. Am J Physiol Endocrinol Metab. 2006; 290: E933-9.

134. Wang Z, Yao T, Pini M, Zhou Z, Fantuzzi G, Song Z. Betaine improved adipose tissue function in mice fed a high-fat diet: a mechanism for hepatoprotective effect of betaine in nonalcoholic fatty liver disease. Am J Physiol Gastrointest Liver Physiol. 2010; 298: G634-42.

135. Ejaz A, Martinez-Guino L, Goldfine AB, Ribas-Aulinas F, De Nigris V, Ribó S, et al. Dietary betaine supplementation increases Fgf21 levels to improve glucose homeostasis and reduce hepatic lipid accumulation in mice. Diabetes. 2016; 65: 902-12.

136. Tabák AG, Jokela M, Akbaraly TN, Brunner EJ, Kivimäki M, Witte DR. Trajectories of glycaemia, insulin sensitivity, and insulin secretion before diagnosis of type 2 diabetes: an analysis from the Whitehall II study. Lancet Lond Engl. 2009; 373: 2215-21.

137. Wilson PWF, Meigs JB, Sullivan L, Fox CS, Nathan DM, D’Agostino RB. Prediction of incident diabetes mellitus in middle-aged adults: the Framingham Offspring Study. Arch Intern Med. 2007; 167: 1068-74. 
138. Nisoli E, Clementi E, Carruba MO, Moncada S. Defective mitochondrial biogenesis: a hallmark of the high cardiovascular risk in the metabolic syndrome? Circ Res. 2007; 100: 795-806.

139. Lin CS, Wu RD. Choline oxidation and choline dehydrogenase. J Protein Chem. 1986; 5: 193-200.

140. Walford GA, Ma Y, Clish C, Florez JC, Wang TJ, Gerszten RE, et al. Metabolite profiles of diabetes incidence and intervention response in the diabetes prevention program. Diabetes. 2016; 65: 1424-33.

141. Song Z, Deaciuc I, Zhou Z, Song M, Chen T, Hill D, et al. Involvement of AMP-activated protein kinase in beneficial effects of betaine on high-sucrose diet-induced hepatic steatosis. Am J Physiol Gastrointest Liver Physiol. 2007; 293: G894-902.

142. Mihalik SJ, Michaliszyn SF, de las Heras J, Bacha F, Lee S, Chace $\mathrm{DH}$, et al. Metabolomic profiling of fatty acid and amino acid metabolism in youth with obesity and type 2 diabetes: evidence for enhanced mitochondrial oxidation. Diabetes Care. 2012; 35: 605-11.

143. Waldram A, Holmes E, Wang Y, Rantalainen M, Wilson ID, Tuohy $\mathrm{KM}$, et al. Top-down systems biology modeling of host metabotypemicrobiome associations in obese rodents. J Proteome Res. 2009; 8: 2361-75.

144. Kim JY, Park JY, Kim OY, Ham BM, Kim HJ, Kwon DY, et al. Metabolic profiling of plasma in overweight/obese and lean men using ultra performance liquid chromatography and Q-TOF mass spectrometry (UPLC-Q-TOF MS). J Proteome Res. 2010; 9: 4368-75.

145. Calvani R, Miccheli A, Capuani G, Tomassini Miccheli A, Puccetti C, Delfini M, et al. Gut microbiome-derived metabolites characterize a peculiar obese urinary metabotype. Int J Obes. 2010; 34: $1095-8$.

146. Kharbanda KK, Mailliard ME, Baldwin CR, Beckenhauer HC, Sorrell MF, Tuma DJ. Betaine attenuates alcoholic steatosis by restoring phosphatidylcholine generation via the phosphatidylethanolamine methyltransferase pathway. J Hepatol. 2007; 46: 314-21.

147. Kathirvel E, Morgan K, Nandgiri G, Sandoval BC, Caudill MA, Bottiglieri T, et al. Betaine improves nonalcoholic fatty liver and associated hepatic insulin resistance: a potential mechanism for hepatoprotection by betaine. Am J Physiol Gastrointest Liver Physiol. 2010; 299: G1068-77.

148. Pan XR, Li GW, Hu YH, Wang JX, Yang WY, An ZX, et al. Effects of diet and exercise in preventing NIDDM in people with impaired glucose tolerance: The Da Qing IGT and Diabetes Study. Diabetes Care. 1997; 20: 537-44.

149. Tuomilehto J, Lindström J, Eriksson JG, Valle TT, Hämäläinen H, Ilanne-Parikka P, et al. Prevention of type 2 diabetes mellitus by changes in lifestyle among subjects with impaired glucose tolerance. N Engl J Med. 2001; 344: 1343-50.

150. Diabetes Prevention Program Research Group. Reduction in the incidence of type 2 diabetes with lifestyle intervention or metformin. N Engl J Med. 2002; 346: 393-403.

151. DREAM (Diabetes REduction Assessment with ramipril and rosiglitazone Medication) Trial Investigators. Effect of rosiglitazone on the frequency of diabetes in patients with impaired glucose tolerance or impaired fasting glucose: a randomised controlled trial. Lancet Lond Engl. 2006; 368: 1096-105.

152. Adamski J. Key elements of metabolomics in the study of biomarkers of diabetes. Diabetologia. 2016; 59: 2497-502.

153. Fuhrer T, Zamboni N. High-throughput discovery metabolomics. Curr Opin Biotechnol. 2015; 31: 73-8.

154. Yu D, Moore SC, Matthews CE, Xiang YB, Zhang X, Gao YT, et al. Plasma metabolomic profiles in association with type 2 diabetes risk and prevalence in Chinese adults. Metabolomics Off J Metabolomic
Soc. 2016; 12: 3. doi: 10.1007/s11306-015-0890-8.

155. Menni C, Fauman E, Erte I, Perry JRB, Kastenmüller G, Shin SY, et al. Biomarkers for type 2 diabetes and impaired fasting glucose using a nontargeted metabolomics approach. Diabetes. 2013; 62: 4270-6.

156. Peddinti G, Cobb J, Yengo L, Froguel P, Kravić J, Balkau B, et al. Early metabolic markers identify potential targets for the prevention of type 2 diabetes. Diabetologia. 2017; 60: 1740-50.

157. Gall WE, Beebe K, Lawton KA, Adam KP, Mitchell MW, Nakhle $\mathrm{PJ}$, et al. alpha-hydroxybutyrate is an early biomarker of insulin resistance and glucose intolerance in a nondiabetic population. PloS One. 2010; 5: e10883. doi: 10.1371/journal.pone.0010883.

158. Ferrannini E, Natali A, Camastra S, Nannipieri M, Mari A, Adam KP, et al. Early metabolic markers of the development of dysglycemia and type 2 diabetes and their physiological significance. Diabetes. 2013; 62: 1730-7.

159. Wang-Sattler R, Yu Z, Herder C, Messias AC, Floegel A, He Y, et al. Novel biomarkers for pre-diabetes identified by metabolomics. Mol Syst Biol. 2012; 8: 615. doi: 10.1038/msb.2012.43.

160. Klein MS, Shearer J. Metabolomics and type 2 diabetes: translating basic research into clinical application. J Diabetes Res. 2016; 2016 : 3898502. doi: 10.1155/2016/3898502.

161. Stumvoll M, Mitrakou A, Pimenta W, Jenssen T, Yki-Järvinen H, Van Haeften $\mathrm{T}$, et al. Use of the oral glucose tolerance test to assess insulin release and insulin sensitivity. Diabetes Care. 2000; 23: 295301.

162. Basu R, Schwenk WF, Rizza RA. Both fasting glucose production and disappearance are abnormal in people with "mild" and "severe" type 2 diabetes. Am J Physiol-Endocrinol Metab. 2004; 287: E55-62.

163. Li L, Krznar P, Erban A, Agazzi A, Martin-Levilain J, Supale S, et al. Metabolomics identifies a biomarker revealing in vivo loss of functional $\beta$-cell mass before diabetes onset. Diabetes. 2019; 68: 2272-86.

164. Palmer ND, Stevens RD, Antinozzi PA, Anderson A, Bergman RN, Wagenknecht LE, et al. Metabolomic profile associated with insulin resistance and conversion to diabetes in the insulin resistance atherosclerosis study. J Clin Endocrinol Metab. 2015; 100: E463-8.

165. Newgard CB. Interplay between lipids and branched-chain amino acids in development of insulin resistance. Cell Metab. 2012; 15: 606-14.

166. Avogaro A, Bier DM. Contribution of 3-hydroxyisobutyrate to the measurement of 3-hydroxybutyrate in human plasma: comparison of enzymatic and gas-liquid chromatography-mass spectrometry assays in normal and in diabetic subjects. J Lipid Res. 1989; 30: 1811-7.

167. Giesbertz P, Padberg I, Rein D, Ecker J, Höfle AS, Spanier B, et al. Metabolite profiling in plasma and tissues of ob/ob and $\mathrm{db} /$ $\mathrm{db}$ mice identifies novel markers of obesity and type 2 diabetes. Diabetologia. 2015; 58: 2133-43.

168. Jang C, Oh SF, Wada S, Rowe GC, Liu L, Chan MC, et al. A branchedchain amino acid metabolite drives vascular fatty acid transport and causes insulin resistance. Nat Med. 2016; 22: 421-6.

169. Lu J, Zhou J, Bao Y, Chen T, Zhang Y, Zhao A, et al. Serum metabolic signatures of fulminant type 1 diabetes. J Proteome Res. 2012; 11: 4705-11.

170. Xu F, Tavintharan S, Sum CF, Woon K, Lim SC, Ong CN. Metabolic signature shift in type 2 diabetes mellitus revealed by mass spectrometry-based metabolomics. J Clin Endocrinol Metab. 2013; 98: E1060-5.

171. Adams SH, Hoppel CL, Lok KH, Zhao L, Wong SW, Minkler PE, 
et al. Plasma acylcarnitine profiles suggest incomplete long-chain fatty acid $\beta$-oxidation and altered tricarboxylic acid cycle activity in type 2 diabetic African-American women. J Nutr. 2009; 139: 1073-81.

172. Pflueger M, Seppänen-Laakso T, Suortti T, Hyötyläinen T, Achenbach $\mathrm{P}$, Bonifacio E, et al. Age- and islet autoimmunity-associated differences in amino acid and lipid metabolites in children at risk for type 1 diabetes. Diabetes. 2011; 60: 2740-7.

173. Suhre K, Meisinger C, Döring A, Altmaier E, Belcredi P, Gieger C, et al. Metabolic footprint of diabetes: a multiplatform metabolomics study in an epidemiological setting. PLoS One. 2010; 5: e13953. doi: 10.1371/journal.pone.0013953.

174. Floegel A, Stefan N, Yu Z, Mühlenbruch K, Drogan D, Joost HG, et al. Identification of serum metabolites associated with risk of type 2 diabetes using a targeted metabolomic approach. Diabetes. 2013; 62: 639-48.

175. Meiliana A, Dewi NM, Wijaya A. Molecular regulation and rejuvenation of muscle stem (satellite) cell aging. Indones Biomed J. 2015; 7: 73-86.

176. Crockett D. Health Catalyst [Internet]. The Real Opportunity of Precision Medicine and How to Not Miss Out [updated 2019 Feb 19; cited 2020 May 29]. Available from: https://www.healthcatalyst. com/real-opportunity-precision-medicine/.

177. Harrer S. Measuring life: sensors and analytics for precision medicine. Bio-MEMS and Medical Microdevices II. 2015; 2015: 951802. doi: 10.1117/12.2178956.

178. International Human Genome Sequencing Consortium. Finishing the euchromatic sequence of the human genome. Nature. 2004; 431: 931-45.

179. Bertini I, Calabrò A, De Carli V, Luchinat C, Nepi S, Porfirio B, et al. The metabonomic signature of celiac disease. J Proteome Res. 2009; 8: 170-7.

180. Bertini I, Cacciatore S, Jensen BV, Schou JV, Johansen JS, Kruhøffer $\mathrm{M}$, et al. Metabolomic NMR fingerprinting to identify and predict survival of patients with metastatic colorectal cancer. Cancer Res. 2012; 72: 356-64.

181. Aimetti M, Cacciatore S, Graziano A, Tenori L. Metabonomic analysis of saliva reveals generalized chronic periodontitis signature. Metabolomics. 2012; 8: 465-74.

182. Nicholson JK, Lindon JC. Systems biology: Metabonomics. Nature. 2008; 455: 1054-6.

183. Marshall E. Metabolic research. Canadian group claims "unique" database. Science. 2007; 315: 583-4.

184. Lindon JC, Nicholson JK. The emergent role of metabolic phenotyping in dynamic patient stratification. Expert Opin Drug Metab Toxicol. 2014; 10: 915-9.

185. Backshall A, Sharma R, Clarke SJ, Keun HC. Pharmacometabonomic profiling as a predictor of toxicity in patients with inoperable colorectal cancer treated with capecitabine. Clin Cancer Res Off J Am Assoc Cancer Res. 2011; 17: 3019-28.

186. Evans WE, McLeod HL. Pharmacogenomics--drug disposition, drug targets, and side effects. N Engl J Med. 2003; 348: 538-49.

187. Ma Q, Lu AYH. Pharmacogenetics, pharmacogenomics, and individualized medicine. Pharmacol Rev. 2011; 63: 437-59.

188. Mancinelli L, Cronin M, Sadée W. Pharmacogenomics: The promise of personalized medicine. AAPS PharmSci. 2000; 2: 29-41.

189. March R. Pharmacogenomics: the genomics of drug response. Yeast Chichester Engl. 2000; 17: 16-21.

190. Carr DF, Alfirevic A, Pirmohamed M. Pharmacogenomics: current state-of-the-art. Genes. 2014; 5: 430-43.

191. Drucker E, Krapfenbauer K. Pitfalls and limitations in translation from biomarker discovery to clinical utility in predictive and personalised medicine. EPMA J. 2013; 4: 7. doi: 10.1186/18785085-4-7.

192. Sun J, Ando Y, Ahilbory-Dieker D, Schnackenberg L, Greenhaw J, Pence L, et al. Systems biology investigation to discover metabolic biomarkers of acetaminophen-induced hepatic injury using integrated transcriptomics and metabolomics. J Mol Biomark Diagn. 2013; S1: 002. doi: 10.4172/2155-9929.S1-002.

193. Abdin AA, Hamouda HE. Mechanism of the neuroprotective role of coenzyme Q10 with or without L-dopa in rotenone-induced parkinsonism. Neuropharmacology. 2008; 55: 1340-6.

194. Ellero-Simatos S, Lewis JP, Georgiades A, Yerges-Armstrong LM, Beitelshees AL, Horenstein RB, et al. Pharmacometabolomics reveals that serotonin is implicated in aspirin response variability. CPT Pharmacomet Syst Pharmacol. 2014; 3: e125. doi: 10.1038/ psp.2014.22.

195. Li M, Wang B, Zhang M, Rantalainen M, Wang S, Zhou H, et al. Symbiotic gut microbes modulate human metabolic phenotypes. Proc Natl Acad Sci USA. 2008; 105: 2117-22.

196. Yapar K, Kart A, Karapehlivan M, Atakisi O, Tunca R, Erginsoy $\mathrm{S}$, et al. Hepatoprotective effect of 1-carnitine against acute acetaminophen toxicity in mice. Exp Toxicol Pathol. 2007; 59: 121-8.

197. Schnackenberg LK, Kaput J, Beger RD. Metabolomics: a tool for personalizing medicine? Pers Med. 2008; 5: 495-504.

198. Ji Y, Hebbring S, Zhu H, Jenkins GD, Biernacka J, Snyder K, et al. Glycine and a glycine dehydrogenase (GLDC) SNP as citalopram/escitalopram response biomarkers in depression: pharmacometabolomics-informed pharmacogenomics. Clin Pharmacol Ther. 2011; 89: 97-104.

199. Abo R, Hebbring S, Ji Y, Zhu H, Zeng ZB, Batzler A, et al. Merging pharmacometabolomics with pharmacogenomics using "1000 Genomes" single-nucleotide polymorphism imputation: selective serotonin reuptake inhibitor response pharmacogenomics. Pharmacogenet Genomics. 2012; 22: 24753.

200. Evans WE, Relling MV. Moving towards individualized medicine with pharmacogenomics. Nature. 2004; 429: 464-8.

201. Pirmohamed M. Personalized pharmacogenomics: predicting efficacy and adverse drug reactions. Annu Rev Genomics Hum Genet. 2014; 15: 349-70.

202. Neavin D, Kaddurah-Daouk R, Weinshilboum R. Pharmacometabolomics informs Pharmacogenomics. Metabolomics Off J Metabolomic Soc. 2016; 12: 121. doi: 10.1007/s11306-0161066-x.

203. Beger RD, Flynn TJ. Pharmacometabolomics in drug safety and drugexposome interactions. Metabolomics. 2016; 12: 123. 10.1007/ s11306-017-1191-1.

204. Weinshilboum R. Inheritance and drug response. N Engl J Med. 2003; 348: 529-37.

205. Li H, Jia W. Cometabolism of microbes and host: implications for drug metabolism and drug-induced toxicity. Clin Pharmacol Ther. 2013; 94: 574-81.

206. Kantae V, Krekels EHJ, Esdonk MJV, Lindenburg P, Harms AC, Knibbe CAJ, et al. Integration of pharmacometabolomics with pharmacokinetics and pharmacodynamics: towards personalized drug therapy. Metabolomics Off J Metabolomic Soc. 2017; 13: 9. doi: 10.1007/s11306-016-1143-1.

207. Clayton TA, Baker D, Lindon JC, Everett JR, Nicholson JK. Pharmacometabonomic identification of a significant hostmicrobiome metabolic interaction affecting human drug metabolism. Proc Natl Acad Sci USA. 2009; 106: 14728-33.

208. Lindon JC, Holmes E, Nicholson JK. Metabonomics techniques and 
applications to pharmaceutical research \& development. Pharm Res. 2006; 23: 1075-88.

209. Nicholson JK, Wilson ID, Lindon JC. Pharmacometabonomics as an effector for personalized medicine. Pharmacogenomics. 2011; 12: 103-11.

210. Nicholson JK, Lindon JC, Holmes E. "Metabonomics": understanding the metabolic responses of living systems to pathophysiological stimuli via multivariate statistical analysis of biological NMR spectroscopic data. Xenobiotica Fate Foreign Compd Biol Syst. 1999; 29: 1181-9.

211. Nicholson JK, Connelly J, Lindon JC, Holmes E. Metabonomics: a platform for studying drug toxicity and gene function. Nat Rev Drug Discov. 2002; 1: 153-61.

212. Yatsunenko T, Rey FE, Manary MJ, Trehan I, Dominguez-Bello MG, Contreras M, et al. Human gut microbiome viewed across age and geography. Nature. 2012; 486: 222-7.

213. Everett JR, Loo RL, Pullen FS. Pharmacometabonomics and personalized medicine. Ann Clin Biochem. 2013; 50: 523-45.

214. Lindon JC, Nicholson JK, Holmes E. The Handbook of Metabonomics and Metabolomics. Philadelphia: Elsevier Science; 2011.

215. Robertson DG, Lindon JC. Metabonomics in Toxicity Assessment. Boca Raton: Taylor \& Francis; 2005.

216. Griffiths WJ. Metabolomics, Metabonomics, and Metabolite Profiling. Cambridge: Royal Society of Chemistry; 2008.

217. Knapp JS, Cabrera WL. Metabolomics: Metabolites, Metabonomics, and Analytical Technologies. New York: Nova Science Publishers; 2009.

218. Nicholson JK, Holmes E, Kinross JM, Darzi AW, Takats Z, Lindon JC. Metabolic phenotyping in clinical and surgical environments. Nature. 2012; 491: 384-92. 